\title{
REVIEW \\ Acute lymphoblastic leukemia: a comprehensive review and 2017 update
}

\author{
$\mathrm{T}^{\text {Terwilliger }}{ }^{1}$ and M Abdul-Hay ${ }^{1,2}$
}

Acute lymphoblastic leukemia (ALL) is the second most common acute leukemia in adults, with an incidence of over 6500 cases per year in the United States alone. The hallmark of ALL is chromosomal abnormalities and genetic alterations involved in differentiation and proliferation of lymphoid precursor cells. In adults, 75\% of cases develop from precursors of the B-cell lineage, with the remainder of cases consisting of malignant T-cell precursors. Traditionally, risk stratification has been based on clinical factors such age, white blood cell count and response to chemotherapy; however, the identification of recurrent genetic alterations has helped refine individual prognosis and guide management. Despite advances in management, the backbone of therapy remains multi-agent chemotherapy with vincristine, corticosteroids and an anthracycline with allogeneic stem cell transplantation for eligible candidates. Elderly patients are often unable to tolerate such regimens and carry a particularly poor prognosis. Here, we review the major recent advances in the treatment of ALL.

Blood Cancer Journal (2017) 7, e577; doi:10.1038/bcj.2017.53; published online 30 June 2017

\section{INTRODUCTION}

Acute lymphoblastic leukemia (ALL) is a malignant transformation and proliferation of lymphoid progenitor cells in the bone marrow, blood and extramedullary sites. While $80 \%$ of ALL occurs in children, it represents a devastating disease when it occurs in adults. Within the United States, the incidence of ALL is estimated at 1.6 per 100000 population. ${ }^{1}$ In 2016 alone, an estimated 6590 new cases were diagnosed, with over 1400 deaths due to ALL (American Cancer Society). The incidence of ALL follows a bimodal distribution, with the first peak occurring in childhood and a second peak occurring around the age of $50 .^{2}$ While doseintensification strategies have led to a significant improvement in outcomes for pediatric patients, prognosis for the elderly remains very poor. Despite a high rate of response to induction chemotherapy, only $30-40 \%$ of adult patients with ALL will achieve long-term remission. ${ }^{3}$

\section{PATHOPHYSIOLOGY}

The pathogenesis of ALL involves the abnormal proliferation and differentiation of a clonal population of lymphoid cells. Studies in the pediatric population have identified genetic syndromes that predispose to a minority of cases of ALL, such as Down syndrome, Fanconi anemia, Bloom syndrome, ataxia telangiectasia and Nijmegen breakdown syndrome. ${ }^{4-7}$ Other predisposing factors include exposure to ionizing radiation, pesticides, certain solvents or viruses such as Epstein-Barr Virus and Human Immunodeficiency Virus. ${ }^{8-10}$ However, in the majority of cases, it appears as a de novo malignancy in previously healthy individuals. Chromosomal aberrations are the hallmark of ALL, but are not sufficient to generate leukemia. Characteristic translocations include $\mathrm{t}(12 ; 21)$ [ETV6-RUNX1], $\mathrm{t}(1 ; 19)$ [TCF3-PBX1], $\mathrm{t}(9 ; 22)[B C R-A B L 1]$ and rearrangement of $M L L .^{11}$ More recently, a variant with a similar gene expression profile to (Philadelphia) Ph-positive ALL but without the BCR-ABL1 rearrangement has been identified. In more than $80 \%$ of cases of this so-called Ph-like ALL, the variant possesses deletions in key transcription factors involved in B-cell development including IKAROS family zinc finger 1 (IKZF1), transcription factor 3 (E2A), early B-cell factor 1 (EBF1) and paired box 5 (PAX5). ${ }^{12}$ Similarly, kinase-activating mutations are seen in $90 \%$ of the Ph-like ALL. The most common of these include rearrangements involving $A B L 1, J A K 2, P D G F R B, C R L F 2$ and EPOR, activating mutations of IL7R and FLT3 and deletion of SH2B3, which encodes the JAK2-negative regulator LNK. ${ }^{13}$ This has significant therapeutic implications as it suggests that Ph-like ALL, which tends to carry a worse prognosis, may respond to kinase inhibitors. In fact, Roberts et al. ${ }^{14}$ showed that cell lines and human leukemic cells expressing $A B L 1, A B L 2, C S F 1 R$ and PDGFRB were sensitive in vitro and in vivo human xenograft models to second-generation TKIs (for example, dasatinib.); those with EPOR and JAK2 rearrangements were sensitive to JAK kinase inhibitors (for example, ruxolitinib); and those with ETV6-NTRK3 fusion were sensitive to ALK inhibitors crizotinib. Furthermore, Holmfeldt et al. ${ }^{15}$ recently described the genetic basis of another subset with poor outcomes, hypodiploid ALL. In near-haploid (24-31 chromosomes) ALL, alterations in tyrosine kinase or Ras signaling was seen in $71 \%$ of cases and in IKAROS family zinc finger 3 (IKZF3) in 13\% of cases. In contrast, low-hypodiploid (32-39 chromosomes) ALL, alterations in p53 (91\%), IKZF2 (53\%) and RB1 (41\%) were more common. Both nearhaploid and low-hypodiploid exhibited activation of Ras- and PI3K-signaling pathways, suggesting that these pathways may be a target for therapy in aggressive hypodiploid ALL. ${ }^{15}$

Most of the clinical manifestations of ALL reflect the accumulation of malignant, poorly differentiated lymphoid cells within the bone marrow, peripheral blood, and, extramedullary sites. Presentation can be nonspecific, with a combination of

\footnotetext{
${ }^{1}$ New York University School of Medicine, New York, USA and ${ }^{2}$ Department of Hematology, New York University Perlmutter Cancer Center, New York, USA. Correspondence: Dr M Abdul-Hay, New York University School of Medicine, 240 East 38th street, 19 Floor, New York 10016, USA.

E-mail: Maher.Abdulhay@nyumc.org

Received 28 March 2017; accepted 21 April 2017
} 
Table 1. WHO classification of acute lymphoblastic leukemia ${ }^{\mathrm{a}}$

B-cell lymphoblastic leukemia/lymphoma, not otherwise specified

B-cell lymphoblastic leukemia/lymphoma, with recurrent genetic abnormalities

B-cell lymphoblastic leukemia/lymphoma with hypodiploidy

B-cell lymphoblastic leukemia/lymphoma with hyperdiploidy

B-cell lymphoblastic leukemia/lymphoma with $\mathrm{t}(9 ; 22)(\mathrm{q} 34 ; \mathrm{q} 11.2)[B C R-A B L 1]$

B-cell lymphoblastic leukemia/lymphoma with $\mathrm{t}(\mathrm{v} ; 11 \mathrm{q} 23)[M L L$ rearranged]

B-cell lymphoblastic leukemia/lymphoma with $\mathrm{t}(12 ; 21)(\mathrm{p} 13 ; \mathrm{q} 22)$ [ETV6-RUNX1]

B-cell lymphoblastic leukemia/lymphoma with $t(1 ; 19)(q 23 ; p 13.3)[T C F 3-P B X 1]$

B-cell lymphoblastic leukemia/lymphoma with $t(5 ; 14)(q 31 ; q 32)[I L 3-I G H]$

B-cell lymphoblastic leukemia/lymphoma with intrachromosomal amplification of chromosome 21 (iAMP21) ${ }^{b}$

B-cell lymphoblastic leukemia/lymphoma with translocations involving tyrosine kinases or cytokine receptors ('BCR-ABL1-like ALL') ${ }^{\mathrm{b}, 14}$

T-cell lymphoblastic leukemia/lymphomas

Early T-cell precursor lymphoblastic leukemia ${ }^{b}$

Abbreviations: ALL, acute lymphoblastic leukemia; WHO, World Health Organization. ${ }^{\mathrm{a} O n}$ the basis of The 2016 revision to the World Health Organization classification of myeloid neoplasms and acute leukemia. ${ }^{23}$ b Provisional entity.

constitutional symptoms and signs of bone marrow failure (anemia, thrombocytopenia, leukopenia). Common symptoms include 'B symptoms' (fever, weight loss, night sweats), easy bleeding or bruising, fatigue, dyspnea and infection. Involvement of extramedullary sites commonly occurs and can cause lymphadenopathy, splenomegaly or hepatomegaly in $20 \%$ of patients. ${ }^{16,17}$ CNS involvement at time of diagnosis occurs in 5-8\% of patients and present most commonly as cranial nerve deficits or meningismus. ${ }^{3}$ T-cell ALL also may present with a mediastinal mass.

Diagnosis is established by the presence of $20 \%$ or more lymphoblasts in the bone marrow or peripheral blood. ${ }^{16}$ Evaluation for morphology, flow cytometry, Immunophenotyping and cytogenetic testing is valuable both for confirming the diagnosis and risk stratification. Lumbar puncture with CSF analysis is standard of care at the time of diagnosis to evaluate for CNS involvement. If the CNS is involved, brain MRI should be performed. Other evaluation includes complete blood count with differential and smear to evaluate the other hematopoietic cell lines, coagulation profiles and serum chemistries. Baseline uric acid, calcium, phosphate and lactate dehydrogenase should be recorded to monitor for tumor lysis syndrome.

\section{CLASSIFICATION}

The first attempt at classifying ALL was the French American British (FAB) morphological criteria that divided ALL into 3 subtypes (L1, L2 and L3) based on cell size, cytoplasm, nucleoli, vacuolation and basophilia. ${ }^{18}$ In 1997, the World Health Organization proposed a composite classification in attempt to account for morphology and cytogenetic profile of the leukemic blasts and identified three types of ALL: B lymphoblastic, T lymphoblastic and Burkitt-cell Leukemia. ${ }^{19}$ Later revised in 2008, Burkitt-cell Leukemia was eliminated as it is no longer seen as a separate entity from Burkitt Lymphoma, and B-lymphoblastic leukemia was divided into two subtypes: B-ALL with recurrent genetic abnormalities and B-ALL not otherwise specified. B-ALL with recurrent genetic abnormalities is further delineated based on the specific chromosomal rearrangement present (Table 1). ${ }^{20}$ In 2016, two new provisional entities were added to the list of recurrent genetic abnormalities and the hypodiploid was redefined as either low hypodiploid or hypodiploid with TP53 mutations. ${ }^{21}$ In adults, B-cell ALL accounts for $\sim 75 \%$ of cases while T-cell ALL comprises the remaining cases.

\section{PROGNOSTIC FACTORS}

Accurate assessment of prognosis is central to the management of ALL. Risk stratification allows the physician to determine the most appropriate initial treatment regimen as well as when to consider allogeneic stem cell transplantation (Allo-SCT). Historically, age and white blood cell count at the time of diagnosis have been used to risk stratify patients. Increasing age portends a worsening prognosis. Patients over the age of 60 have particularly poor outcomes, with only $10-15 \%$ long-term survival. ${ }^{22}$ Age is at least in part a surrogate for other prognosticators as the elderly tend to have disease with intrinsic unfavorable biology (for example, Philadelphia chromosome positive, hypodiploidy and complex karyotype), more medical comorbidities and inability to tolerate standard chemotherapy regimens but helps guide therapy nonetheless. In the largest prospective trial to determine optimal treatment, MRC UKALL XII/ECOG E2993 found a significant difference of disease-free (DFS) and overall survival (OS) based on age using a cutoff of 35 in Ph-negative disease. ${ }^{23}$ Similarly, they found an elevated white blood cell count at diagnosis, defined as $>30 \times 10^{9}$ for B-ALL or $>10010^{9}$ for T-ALL, was an independent prognostic factor for DFS and OS. On the basis of these results, Phnegative disease could be categorized as low risk (no risk factors based on age or WBC count), intermediate risk (age $>35$ or elevated WBC count), or high risk (age $>35$ and elevated WBC count). The 5-year OS rates based on these risk categories were 55 , 34 and $5 \%$, respectively. ${ }^{23}$

Although clinical factors play an important role in guiding therapy, cytogenetic changes have a significant role in risk determination. The cytogenetic aberration with the greatest impact on prognosis and treatment is the presence of the Philadelphia chromosome, $t(9 ; 22)$. The prevalence of $t(9 ; 22)$ in adult ALL can range from $15-50 \%$ and increases with age. ${ }^{24} \mathrm{Ph}-$ positivity has implications both in terms of prognosis and for treatment. Historically, Ph-positive ALL has a 1-year survival of around $10 \%$. However, with the development of TKIs, survival has improved and thus the Ph-status of all patients must be obtained prior to starting therapy. Subsequent analysis of MRC UKALL XII/ ECOG E2993, identified cytogenetic subgroups of Ph-negative disease with inferior outcomes. These included $\mathrm{t}(4 ; 11), K M T 2 A$ translocation, $\mathrm{t}(8 ; 14)$, complex karyotype $(\geqslant 5$ chromosomal abnormalities) and low hypodiploidy (30-39 chromosomes)/near triploidy (60-78 chromosomes). In contrast, patients with hyperdiploidy and del(9p) had a significantly better outcome. ${ }^{25}$ In a later study, the Southwest Oncology Group (SWOG) showed that among the 200 study patients, cytogenetic profile was a more important prognostic factor than age or WBC count. ${ }^{26}$ More recently, a subset of high-risk ALL without $t(9 ; 22)$ has been 
identified with a genetic profile similar to that of Ph-positive ALL. This so called, Ph-like ALL has been associated with poor response to induction chemotherapy, elevated minimal residual disease and poor survival. $13,14,27$

In addition to disease characteristics at the outset, it has long been recognized that response to initial therapy predicts outcome. Historically, treatment response was evaluated morphologically. Recently, it has become standard practice to evaluate patients for minimal residual disease (MRD) using molecular techniques such as flow cytometry and PCR. ${ }^{28}$ Several studies have shown the importance of MRD in assigning risk. ${ }^{29-34}$ Bruggemann et al. ${ }^{29}$ re-stratified standard-risk patients to low risk, intermediate risk and high risk with relapse rates of $0 \%, 47 \%$ and $94 \%$, respectively, based on the persistence of elevated MRD, defined as $>10^{-4}$. In a multivariate analysis of 326 adolescent and adult patients with high-risk Ph-negative ALL treated in The Programa Espanol de Tratamientos en Hematologia (PETHEMA ALL-AR-03), Ribera et al. ${ }^{35}$ showed that poor MRD clearance, defined as levels $>1 \times 10^{-3}$ after induction and levels $>5 \times 10^{-4}$ after early consolidation by flow cytometry, was the only significant prognostic factor for disease-free and overall survival.

On the basis of what is known about prognostic factors in adult ALL, the National Comprehensive Cancer Network (NCCN) has developed recommendations to approach risk stratification. ${ }^{16}$ The National Cancer Institutes defines adolescent and young adults (AYA) to be those aged 15-39 years. The NCCN recognizes that AYA may benefit from treatment with pediatric-inspired regimens and thus are considered separately from adults $>40$ years. ${ }^{36,37}$ Both age groups are then stratified into high-risk Ph-positive and standard-risk Ph-negative subgroups. The Ph-negative subgroup can further be categorized as high-risk based on the presence of MRD, elevated WBC (defined above) or unfavorable cytogenetics (defined above).

\section{ESTABLISHED TREATMENTS}

The structure of treatment of adult ALL has been adapted from pediatric protocols. Unfortunately, while long-term survival approaches $90 \%$ for standard-risk pediatric ALL, the success rate is much more modest in adults. Chemotherapy consists of induction, consolidation and long-term maintenance, with CNS prophylaxis given at intervals throughout therapy. The goal of induction therapy is to achieve complete remission and to restore normal hematopoiesis. The backbone of induction therapy typically includes vincristine, corticosteroids and an anthracycline..$^{38,39}$ In the Cancer and Leukemia Group B 8811 trial, Larsen et al. ${ }^{40}$ achieved a complete response rate of $85 \%$ and a median survival of 36 months. The 4-week long induction schedule consists of cyclophosphamide on day 1, 3 consecutive days of daunorubicin, weekly vincristine, biweekly L-asparaginase and 3 weeks of prednisone. ${ }^{40}$ Due to high induction-related mortality, one-third dose reductions of cyclophosphamide and daunorubicin were implemented for patients older than 60 and the duration of prednisone was shortened to 7 days in this age group. The role of L-asparaginase, while standard in pediatric protocols, is a challenge in adults at times due to the increased rate of adverse events. ${ }^{41}$ In fact, in the UKALL 14 Trial, Patel et al. ${ }^{42,43}$ demonstrated that asparaginase toxicity was the leading cause of induction-related mortality and the protocol was amended to omit asparaginase for patients over the age of 40 . The MRC UKALL XII/ECOG $2993^{23}$ regimen utilizes a similar structure to CALGB 8811. Induction is divided into two phases of four weeks. In contrast to CALGB 8811, cyclophosphamide is omitted in phase I of induction, but a single dose of intrathecal methotrexate is added for CNS prophylaxis. In phase II of induction, cyclophosphamide is introduced along with cytarabine, oral 6-mercaptopurine (6-MP), four additional intrathecal doses of methotrexate, and cranial radiation if CNS is positive. After induction therapy, patients received three cycles of intensification therapy of methotrexate with leucovorin rescue and L-asparaginase. Eligible patients with high-risk disease and a matched donor, then underwent Allo-SCT. All others were randomized to standard consolidation/maintenance or autologous stem cell transplant. This study yielded a complete response rate of $91 \%$ and an overall 5-year survival of $38 \%{ }^{23}$

The Hyper-CVAD (HCVAD)/ Methotrexate-cytarabine regimen is utilizes an alternative structure to the approaches described above. It consists of four cycles of hyperfractionated cyclophosphamide, vincristine, doxorubicin and dexamethasone alternated with four cycles of high dose cytarabine and methotrexate. ${ }^{44}$ CNS prophylaxis with 4-16 doses of intrathecal chemotherapy depending on predetermined risk of CNS disease. HCVAD has demonstrated similar efficacy to the ECOG trial with a 92\% complete response rate and 32\% 5-year disease-free survival. ${ }^{44}$ Several studies have suggested a benefit to using dexamethasone as opposed to prednisone due to the ability of dexamethasone to achieve higher concentrations in the CNS. Despite a reduction in CNS relapse and improved event-free survival, dexamethasone has increased risk of adverse events compared to prednisone. Since there have been no studies comparing overall survival, the benefit of one corticosteroid over the other has not been established. $^{45,46}$

After induction, eligible patients may go on to Allo-SCT while all others go on to intensification/consolidation and maintenance. ${ }^{47}$ Consolidation varies in the different protocols, but generally utilize similar agents to induction and includes intrathecal chemotherapy and cranial radiation for CNS prophylaxis at times. Maintenance therapy consists of daily 6-MP, weekly methotrexate, and vincristine and a 5-day prednisone pulse every 3 months. Maintenance is administered for 2-3 years after induction, beyond which it has not been shown to have benefit. ${ }^{17,47}$

Special consideration must be made in the treatment of Ph-positive ALL. Historically, Ph-positive ALL was a very bad player with 5 -year survival $\sim 5-20 \%$ and Allo-SCT being the only chance for cure. ${ }^{48,49}$ Various studies have found that matchedsibling Allo-SCT may improve long-term survival to $35-55 \%$, however, availability of matched donors represents a significant limitation. ${ }^{49-51}$ The advent of TKIs marked a turning point in the treatment of Ph-positive ALL. Thomas et al. ${ }^{52,53}$ showed that when added to traditional HCVAD, imatinib resulted in improvement in 3 -year OS (54 vs 15\%). Despite these promising results, some patients fails treatment due to resistance or relapse, particularly in the CNS where imatinib has limited penetration. ${ }^{54}$ Secondgeneration $A B L$ kinase inhibitor, dasatinib, was developed as a dual src/abl kinase inhibitor for chronic myeloid leukemia with a superior resistance profile to imatinib. Dasatinib was also shown to penetrate the blood-brain barrier and was effective at treating CNS disease in a mouse model and pediatric Ph-positive ALL. ${ }^{55}$ In the first study of dasatinib in Ph-positive ALL, Ravandi et al. ${ }^{56}$ found a CR rate of $96 \%$ when dasatinib was combined with HCVAD, and a 5 -year OS of $46 \%$. In a subsequent, multi-center trial HCVAD plus dasatinib achieve a 3-year OS of $71 \%$ in adult patients younger than $60 .{ }^{57}$ In addition, prior resistance to imatinib did not preclude a response to dasatinib. ${ }^{58}$ In addition, dasatinib was shown to be effective in inducing complete remission when used in combination with prednisone and intrathecal methotrexate. ${ }^{59}$ In the GIMEMA LAL1205 study, ${ }^{59}$ it was noted that the most common cause of relapse was a T315I mutation in the ABL kinase doman. Ponatinib, a third-generation TKI with the ability to inhibit most BCR-ABL1 kinase domain mutations, has recently gained approval for resistant Ph-positive ALL. The PACE trial ${ }^{60}$ demonstrated the ability of ponatinib to generate a cytogenetic response in $47 \%$ of Ph-positve ALL patients after dasatinib failure. When compared head-to-head with dasatinib, ponatinib achieved significantly better 3-year EFS and OS when used as frontline 
therapy. ${ }^{42,61,62}$ These data suggest that ponatinib may soon have a role in the frontline therapy of Ph-positive ALL.

Recent studies have suggested that the AYA population, defined as aged 15-39, may benefit from treatment on pediatric-inspired protocols. In an analysis of 262 AYA patients aged 16-21 on pediatric protocol CCG 1961, Nachman et al. ${ }^{63}$ reported a 5 -year EFS of $68 \%$. Furthermore, patients in the study that were treated on augmented intensity therapy performed better. In a prospective study, Stock et al. ${ }^{64}$ treated 317 patients aged 17-39 on Children's Oncology Group AALL0232 protocol. Median EFS approached 60 months, which was statistically higher than the null hypothesis of 32 months. OS at 2-years was $78 \%{ }^{64}$ Similarly, The Group for Research on Adult Acute Lymphoblastic Leukemia (GRAAL), compared 225 patients up to the age of 60 who were treated on pediatric-inspired regimen and historical data from 712 adults treated on standard adult regimen LALA-93. ${ }^{36}$ They observed a significant improvement in CR, EFS and OS, which was most marked in patients younger than age of 45 years. In fact, in patients older than 45 years, there was a significantly higher rate of chemotherapy-related events compared to younger patients, suggesting that an age cutoff for pediatric-inspired regimens is appropriate. However still one of the adult regimens is still considered for AYA patients is HCVAD \pm rituximab. An MD Anderson Cancer Center study revealed no significant difference in CR rate or OS in AYA patients treated with HCVAD \pm rituximab vs an augmented-BerlinFrankfurt-Munster regimen. ${ }^{65}$

\section{REFRACTORY/RELAPSED DISEASE}

While $85-90 \%$ of patients go into remission after induction therapy, there are subsets that are refractory to induction therapy. In addition, a majority of patients that do achieve CR go on to relapse. Options of salvage therapy for relapsed/refractory $(r / r) \mathrm{Ph}-$ negative disease include augmented cytotoxic chemotherapy, reformulated single-agent chemotherapy and novel monoclonal antibodies. Augmented-HCVAD for salvage therapy was inspired by pediatric regimens that employ intensified doses of vincristine, corticosteroids and asparaginase in frontline therapy. Faderl et $a .^{66}$ treated 90 patients (median age 34) with relapsed or refractory disease with HCVAD in which the dosing of vincristine, dexamethasone and asparaginase where intensified as follows: vincristine $2 \mathrm{mg}$ i.v. weekly on days 1, 8 and 15; dexamethasone $80 \mathrm{mg}$ i.v. or orally (p.o.) on days $1-4$ and $15-18$, and pegaspargase 2500 units $/ \mathrm{m}^{2}$ i.v. on day 1 of the hyper-CVAD courses $(1,3,5$ and 7$)$ and day 5 of the methotrexate/cytarabine courses $(2,4,6$ and 8$)$. The majority of patients were in first salvage and ten patients were primary refractory, and patients with prior exposure to HCVAD were not excluded. Complete response was observed in $47 \%$ of the patients, with a median duration of 5 months. Median DFS and OS were 6.2 and 6 months respectively. ${ }^{66}$ It was also noted that the addition of rituximab to HCVAD for B-ALL with high CD20 expression to improve the activity of this salvage regimen.

In patients with relapsed/refractory ALL, particularly those with multiple relapses, toxicity of multi-agent cytotoxic therapy may be limiting. Therefore, attempts have been made at salvage therapy with a single agent. In subgroup analysis of 70 patients receiving second salvage therapy with a single agent (most commonly vinorelbine (6), clofarabine (5), nelarabine (4) and topotecan (4)), only 3 achieved a complete response. ${ }^{67,68}$ Vincristine sulfate liposomes injection (VSLI) was developed to overcome the dosing and pharmacokinetic limitations of nonliposomal vincristine (VCR). In a phase II study in adults with Ph-negative ALL in their second or greater relapse, VSLI was administered weekly at a dose of $2.25 \mathrm{mg} / \mathrm{m}^{2}{ }^{29}$ Of the 65 adults enrolled, $20 \%$ achieved complete response with a median duration of 23 weeks (range 5-66). Twelve patients were bridged to Allo-SCT, with five long-term

survivors. ${ }^{69}$ This study led to the accelerated approval of VSLI for salvage therapy in 2012. VSLI was well tolerated with a side effect profile similar to standard-formulation VCR, despite the massive cumulative doses of VCR achieved.

Despite the modest ability of cytotoxic chemotherapy to prolong survival, the only hope for long-term survival in these regimens remains Allo-SCT. However, recently novel monoclonal antibodies have transformed the landscape of salvage therapy by offering a chance at cure may be without Allo-SCT. The first of these is the bispecific anti-T-cell receptor/anti-CD19 antibody, blinatumomab. The proposed mechanism of action of blinatumomab is that it engages $T$ cells to activate a B-cell specific inflammatory and cytolytic response. ${ }^{70}$ Blinatumomab was first studied in patients with MRD positive ALL. In one trial, $80 \%$ of patients became MRD negative after the first cycle of blinatumomab, with $60 \%$ of patients remaining in CR at a median follow-up of 33 months. ${ }^{71}$ Importantly, in a multi-center trial (BLAST), Gokbuget et al. ${ }^{72}$ confirmed the ability of blinatumomab to eliminate MRD and showed no difference in OS or relapse-free survival (RFS) between patients who received Allo-SCT during the first CR (CR1) and those who did not. Based on these results, blinatumomab was studied for relapsed/refractory Ph-negative ALL. The landmark study was a multi-center, single-arm, openlabel phase 2 trial in which 189 patients with primary refractory and relapsed ALL received single-agent therapy with blinatumomab. CR was achieved after 2 cycles in 43 with $82 \%$ achieving MRD negativity. The median response duration and the overall survival were 9 and 6 months, respectively. ${ }^{73}$ Based on these results, blinatumomab was approved by the FDA for relapsed and refractory ALL in 2016. Subsequently, blinatumomab was compared to investigator's choice of chemotherapy for $\mathrm{r} / \mathrm{r} \mathrm{Ph}$-negative ALL in the phase 3 randomized trial (TOWER study). The blinatumomab study group $(n=271)$ had a median survival of 7.7 months $(95 \%$ confidence interval $(\mathrm{Cl})$ : $5.6,9.6)$ versus 4.0 months $(95 \% \mathrm{Cl}: 2.9,5.3)$ for standard of care $(n=134)$ $(P=0.012$, hazards ratio $(\mathrm{HR}), 0.71) .^{74}$ The study was terminated early for efficacy based on these results. Blinatumomab has also been investigated for $\mathrm{r} / \mathrm{r}$ Ph-positive disease. In the ALCANTARA trial, standard dose blinatumomab was given for up to 5 cycles in 45 patients. CR was observed in 36 and $88 \%$ of whom were MRD negative, and with a median follow-up of 9 months, the median OS was 7.1 months. ${ }^{75}$ Future investigation is planned for the frontline use of blinatumomab for Ph-positive ALL in conjunction with TKIs. ${ }^{76}$ The toxicity profile of blinatumomab is acceptable. The most frequent adverse events include fever, chills, neutropenia, anemia and hypogammaglobulinemia. ${ }^{3}$ More significant adverse events are rare, but include cytokine release syndrome, altered mental status and seizures. ${ }^{73}$ Death from sepsis that is thought to be treatment-related has been reported.

Frontline therapy is the same for B-cell ALL and T-cell ALL. However, owing to different biology of the two subtypes, T-cell ALL is not amenable to salvage treatment with blinatumomab. Fortunately, alternative options for salvage therapy exist. Nelarabine is a T-cell specific purine nucleoside analog that is FDA approved for $r / r$ T-cell ALL. Nelarabine accumulates in T cells at a high rate and incorporates into DNA causing an inhibition of DNA synthesis and subsequent apoptosis. ${ }^{77}$ In a phase 2 , openlabel, multi-center trial, nelarabine was administered on alternate day schedule (days 1, 3 and 5) at $1.5 \mathrm{~g} / \mathrm{m}^{2} /$ day for $\mathrm{r} / \mathrm{r}$ T-cell ALL. Cycles were repeated every 22 days. The rate of complete remission was $31 \%(95 \% \mathrm{Cl}, 17,48 \%)$, the median DFS and OS were 20 weeks with a 1 -year OS of $28 \%{ }^{77}$ However, there is still more that needs to be done to achieve a better response and overall survival in patients with relapsed/refractory B- and T-cell ALL. 


\section{FUTURE THERAPIES}

1-Monoclonal antibodies

A-CD22-Directed therapy. CD22 is a B-lineage differentiation antigen expressed in B-cell ALL in $50-100 \%$ of adults and $90 \%$ of children. ${ }^{7-80}$ Upon binding of an antibody, CD22 is rapidly internalized, thus making it an attractive target for delivering immunotoxin to leukemic cells. ${ }^{81}$

Epratuzumab. Epratuzumab is an unconjugated monoclonal antibody targeting CD22 that has been studied in pediatric and adult relapsed/refractory ALL. Epratuzumab was evaluated in 15 pediatric patients as part of a salvage therapy regimen. The antibody was administered as a single-agent followed by the antibody in combination with standard re-induction chemotherapy. The treatment resulted in a CR in 9 of the patients, with 7 achieving complete MRD clearance at the end of re-induction. ${ }^{82} \mathrm{~A}$ phase 2 study in adults with relapsed/refractory disease evaluated the addition of epratuzumab to clofaribine/cytarabine. The study demonstrated a superior response rate when compared to historical data of clofaribine/cytarabine alone. ${ }^{83}$ More recently, epratuzumab conjugated to the topoisomerase I inhibitor, SN-38, has been shown to have activity against B-cell lymphoma and leukemia cell lines in in vitro and in vivo preclinical studies. ${ }^{84}$

Inotuzumab ozogamicin. Inotuzumab ozogamicin ( $\operatorname{lnO})$ is a monoclonal antibody against CD22 that is conjugated to calicheamicin, a potent cytotoxic compound that induces double-strand DNA breaks. ${ }^{85}$ Upon internalization of the immunoconjugate, calicheamicin binds DNA and causes doublestranded DNA breaks, which induces apoptosis. Preclinical studies showed that calicheamicin conjugated to an anti-CD22 antibody resulted in potent cytotoxicity leading to regression of B-cell lymphoma and prevention of xenograft establishment at picomolar concentrations. ${ }^{86}$ Phase 1 studies in non-hodgkin lymphoma (NHL) established a maximum tolerated dose of $1.8 \mathrm{mg} / \mathrm{m}^{2}$ InO given intravenously every 3 to 4 weeks. ${ }^{87}$ Subsequently, InO was studied in adults with relapsed/refractory ALL. ${ }^{88}$ In this phase 2 trial, 90 patients were treated with either a single infusion every 3 to 4 weeks or weekly InO infusions. Cumulative doses were equivalent among the two treatment strategies. Overall response rate was $58 \%$, with similar response between the two dosing schedules. Median survival was 6.2 months, with a non-significant benefit seen in weekly dosing. However, toxicity was greatly improved by weekly dosing, with a significant reduction in fever, hepatotoxicity and veno-occlusive disease. ${ }^{89} \mathrm{~A}$ second phase 2 study of 35 patients with CD22+ ALL in second salvage or later showed similar complete response rate (66\%) and median overall survival (7.4 months). ${ }^{90}$ Based on these results, Kantarjian et al. ${ }^{91}$ compared weekly dosing of InO to standard chemotherapy for relapsed/refractory ALL. The rate of complete remission was significantly higher in the InO group versus standard chemotherapy $80.7 \%(95 \% \mathrm{Cl}, 72.1-87.7)$ vs $29.4 \%$ (95\% Cl, 21.0-38.8), $P<.001){ }^{91}$ Progression-free survival (5 months vs 1.8 months) and overall survival (7.7 months vs 6.7 months) were also significantly prolonged with InO compared to standard chemotherapy. The most common adverse events of InO treatment included thrombocytopenia and neutropenia. Veno-occlusive liver disease occurred in $11 \%$ of patients treated with InO compared to $1 \%$ of those receiving standard chemotherapy. ${ }^{91}$ Based on these results, InO was granted Breakthrough Therapy status by the FDA in 2015 and is a strong candidate for expedited approval for relapsed/ refractory ALL.

InO has also been studied in frontline therapy in combination with low-intensity HCVAD for elderly patients $>60$ years. ${ }^{92}$ These patients are prone to adverse events from chemotherapy and have poorer outcomes than their younger counterparts. In attempt to reduce toxicity, doxorubicin was eliminated from induction therapy, and cyclophosphamide, prednisone, methotrexate and cytarabine were given at reduced doses. InO was given during each of the first four courses. The regimen was well tolerated and produced superior 1-year OS as compared to historical data among similar patient population (78 vs $60 \%$ ). ${ }^{92}$

Moxetumomab pasudodotox. A third anti-CD22 monoclonal antibody, moxetumomab, is currently in development for treatment of pediatric and adult ALL. Moxetumomab is a reformulation of an older study drug, BL22, which was composed the variable region $\left(F_{v}\right)$ of an anti-CD22 monoclonal antibody fused to Pseudomonas aeruginosa exotoxin $\mathrm{A} .^{93} \mathrm{BL} 22$ was shown to be highly active against Hairy Cell Leukemia in a phase 2 trial. ${ }^{94}$ In a phase 1 trial of children with relapsed/refractory ALL, BL22 was well tolerated and exhibited anti-leukemic activity at all doses, but clinical benefits were transient and modest. ${ }^{95}$ Therefore, BL22 was reformulated as moxetumomab to contain a $F_{v}$ fragment with greater affinity for CD22. In phase 1 trials, moxetumomab showed an overall activity rate of $70 \%$ in children with relapsed/refractory ALL. ${ }^{96}$ Enrollment is ongoing for a phase $1 / 2$ trial of moxetumomab pasudodotox for treatment of relapsed/refractory ALL in adults. ${ }^{97}$

Combotox. Combotox is a combination immunotoxin that contains a 1:1 mixture of anti-CD19 and anti-CD22 antibodies, both conjugated to the cytotoxin deglycosylated ricin-A chain. In pediatric patients with relapsed/refractory ALL, combotox led to a $\mathrm{CR}$ in 3 of 17 patients. In addition, six additional patients experienced a $>95 \%$ reduction in peripheral blasts. ${ }^{98}$ In adults with relapsed/refractory disease, combotox led to reduction of peripheral blasts in all patients; however, a durable response was not seen as blast count rebounded quickly after the final dose of combotox. $^{99}$ A phase I trial is recruiting patients to evaluate combotox in combination with cytarabine for adults with relapsed/refractory ALL (NCT01408160).

$B$-CD20. $C D 20$ is a B-lineage specific antigen expressed at nearly all stages of differentiation on the surface of both normal and malignant B-cells. Signaling through CD20 plays a role in cell cycle progression, differentiation pathways and regulation of apoptosis. CD20 is expressed in $40-50 \%$ of precursor lymphoblasts, and confers a worse prognosis. ${ }^{100}$ Moreover, CD20-positive leukemia responds poorly to dose intensification, highlighting the need for targeted therapy. The addition of rituximab, a first-generation antiCD20 monoclonal antibody, has improved outcomes in these patients, but resistance to rituximab represents a limitation to its use.

Ofatumumab. Ofatumumab is a second-generation anti-CD20 antibody with a distinct binding site from that of rituximab. Ofatumumab was first showed to have benefit in fludarabinerefractory chronic lymphocytic leukemia, irrespective of prior rituximab exposure. ${ }^{101}$ Ofatumumab induces higher levels of complement-dependent cytotoxicity (CDC) and has a slower dissociation rate than rituximab, and thus holds promise for CD20+ lymphoid malignancies both as frontline therapy and as salvage for rituximab-refractory disease. ${ }^{102,103}$ In a phase 2 study, ofatumumab was used in combination with HCVAD in patients with either newly diagnosed pre-B CD20+ ALL or those who had completed a single course of chemotherapy. In all study patients, CD20+ expression was $>1 \% .{ }^{104}$ Ofatumumab was administered at a dose of 2 grams on days 1 and 11 of the first 4 cycles of induction therapy. All but one patient (98\%) achieved CR after cycle 1 and $93 \%$ of patients were negative for MRD at end induction. The 3-year CR and OS rates were $78 \%$ and $68 \%$, respectively. ${ }^{105}$ This is similar to benefits seen when rituximab was used as frontline therapy in CD20+ ALL. ${ }^{106}$ Ofatumumab represents a potential alternative frontline therapy for CD20+ 
pre-B-ALL and an option for patients who failed a rituximab-based regimen.

Obinutuzumab. Another novel anti-CD20 monoclonal antibody, obinutuzumab, has shown promise in preclinical trials for CD20positive B-ALL. Obinutuzumab was engineered to have enhanced affinity for the FcyRllla receptor on effector cells and thus enhanced antibody-dependent cell-mediated cytotoxicity (ADCC). ${ }^{107}$ This compromises the ability of obinutuzumab to activate complement and predictably, CDC was inferior to that of rituximab and ofatumumab in vitro. However, obinutuzumab induced direct cell death and ADCC more rapidly and effectively. When all three mechanisms of cell death were evaluated together in B-cell depletion assays, obinutuzumab was more effective than either rituximab or ofatumumab achieving higher maximal depletion and lower $\mathrm{EC}_{50}$. Furthermore, obinutuzumab was superior in inhibiting growth in NHL xenograft models. ${ }^{107}$ Awasthi et al. ${ }^{108}$ compared obinutuzumab to ritixumab in pre-B-ALL cell lines and found obinutuzumab to be superior in inducing cell death and ADCC. In a pre-B-ALL xenograft model, overall survival was improved with obinutuzumab compared to ritixumab. ${ }^{108}$ In clinical trials, obinutuzumab has been added to chlorambucil for treatment of adults with CLL and shown to prolong progressionfree survival and improve complete response rate when compared to rituximab and chlorambucil. ${ }^{109}$ Taken together, these results suggest a role for obinutuzumab in CD20+ pre-B-ALL.

REGN1979. REGN1979 is a biallelic monoclonal antibody targeting CD20 and CD3. The theory of REGN1979 is similar to that of blinatumumab, to engage $T$ cells and B-cells thus resulting in activation of T-cell immune response against B-cells. REGN1979 prevented the establishment of lymphoma xenografts and led to complete tumor regression in murine models. ${ }^{110}$ In addition, in a primate model, REGN1979 led to a complete and durable depletion of B-cells. When compared to treatment with rituximab, treatment with REGN1979 led to significantly more profound depletion of B-cells. ${ }^{110}$ The safety of REGN1979 was established in a phase 1 trial of 25 patients with NHL and CLL. Dose-dependent antitumor activity was observed. The most significant adverse events include cytokine release syndrome (CRS) and hypotension. ${ }^{111}$ A phase 2 trial of REGN1979 in relapsed/refractory ALL is currently open for recruitment (NCT02651662).

C-CD19. CD19 is the most widely expressed B-lineage specific antigen, expressed during all stages of differentiation, but lost on maturation to plasma cells. CD19 serves as a co-receptor for the B-cell surface immunoglobulin and its activation triggers a phosphorylation cascade involving src-family kinases and PI3K as well as the activation of c-myc, leading to proliferation and differentiation. ${ }^{112-114}$ CD19 is expressed in nearly all B-cell leukemias, and is rapidly internalized upon binding of an antibody, making it an ideal candidate for immunoconjugate therapy. $^{115}$

Coltuximab ravtansine (SAR3419). Coltuximab ravtansine is an anti-CD19 humanized monoclonal antibody conjugated to a semisynthetic maytansinoid compound, an anti-tubulin molecule similar to vincristine. Maytansinoids are more potent than vinca alkaloids, and thus have been of limited use in systemic therapy due to unacceptable toxicity. ${ }^{116}$ However, this potency makes them attractive candidates for targeted delivery. In preclinical studies, SAR3419 monotherapy delayed progression in pre-B-ALL xenografts and provided objective response. When used in combination with a chemotherapy regimen that mimicked pediatric induction protocols, SAR3419 was effective at prolonging the duration of remission. ${ }^{117}$ SAR3419 was then evaluated in a Phase 1 clinical trial with CD19+ B-cell lymphoma. Dose-limiting toxicities were reversible blurred vision and neuropathy. A maximum tolerated dose (MTD) of $160 \mathrm{mg} / \mathrm{m}^{2}$ administered once every three weeks was established. Reduction of tumor size was seen in $74 \%$ of patients, including $47 \%$ of patients with rituximabresistant disease. ${ }^{118}$ An initial phase 2 clinical trial was terminated early due to low response rate of $25 \% .^{119}$

Denintuzumab mafodotin (SGN-CD19A). A second anti-CD19 conjugated monoclonal antibody, denintuzumab mafodotin, is currently in development. In this case, the antibody is linked to the microtubule-disrupting agent monomethyl auristatin F (MMAF). In a phase 1 study of patients with relapsed/refractory B-ALL or aggressive B-cell lymphomas, a complete response rate of $35 \%$ was observed. ${ }^{120}$ Dosing interval of 3 weeks was shown to be superior to weekly dosing. An MTD was identified at $5 \mathrm{mg} / \mathrm{kg}$ q3wk. Interestingly, among $\mathrm{Ph}$-positive B-ALL, the response rate was $63 \%$, leading to recruitment of $\mathrm{Ph}$-positive patients for an expansion cohort. These results warrant further evaluation of denintuzumab mafodotin for relapsed/refractory ALL.

ADCT-402. ADCT-402 is the newest anti-CD19 monoclonal antibody to enter development. It is a humanized monoclonal antibody conjugated to a pyrrolobenzodiazepine (PBD). PBDs are a class of natural antibiotics derived from actinomycetes bacteria that inhibit cell division by binding in the minor groove of DNA and cross-linking strands of DNA. In vivo studies show superior antitumor activity of ADCT-402 against CD19-positive lymphoma than maytansinoid or auristatin based therapy. ${ }^{121}$ A phase 1 trial of ADCT-402 for relapsed/refractory ALL is underway (NCT02669264).

$D$-CD25. CD25 is a cell surface antigen and component of the Interleukin-2 receptor (IL-2 R) heterotrimer. ${ }^{122}$ Binding of IL-2 R by its ligand activates JAK/STAT, MAP kinase and phosphoinositide 3-kinase (PI3K) signaling pathways, leading to cell proliferation. $\mathrm{IL}-2 \mathrm{R}$ is rapidly recycled upon binding of its ligand. ${ }^{123}$ The IL-2 R signaling pathway is particularly activated in T-cell immune response, and has thus been an attractive target for posttransplant immunosuppression. In some studies, CD25 expression has been as high as $30 \%$ of pre-B-ALL lymphoblasts, including $100 \%$ expression among the $\mathrm{Ph}$-positive subset. ${ }^{124}$

ADCT-301. ADCT-301 is a monoclonal antibody against CD25 conjugated to a PBD. In preclinical studies, ADCT-301 has been shown to be potently cytotoxic to CD25-positive anaplastic large cell lymphoma and Hodgkin lymphoma cell lines. In vivo, ADCT-301 exhibited antitumor activity in xenograft and disseminated mouse models. ${ }^{122}$ A phase 1 trial is recruiting participants for ADCT-301 in relapsed/refractory AML and ALL (NCT02588092).

\section{2-Proteasome inhibitor (Bortezomib)}

Bortezomib, a proteasome inhibitor, was first approved for the treatment of multiple myeloma. Preclinical studies have suggested a synergistic role of bortezomib with dexamethasone and additive effects to standard chemotherapy agents in acute leukemias. ${ }^{125}$ As a single agent, bortezomib did not produce durable responses in patients with relapsed/refractory ALL, despite demonstrable proteasomal inhibition. ${ }^{126}$ However, in a phase 2 study, bortezomib in combination with vincristine, dexamethasone, pegylated asparaginase and doxorubicin produced a response rate of $80 \%$ in children with relapsed/refractory pre-B-ALL. ${ }^{127}$ In a recent phase 2 COG trial, re-induction chemotherapy plus bortezomib resulted in a complete response in $68 \%$ of children with relapsed pre-BALL. ${ }^{128}$ Due to it's ability to inhibit the NF-KB and NOTCH1 signaling pathways, bortezomib is being studied as frontline therapy in T-cell ALL. Recruitment is ongoing for a phase 3 trial of standard chemotherapy with or without bortezomib in children and young adults (age 2-30) with newly diagnosed T-cell ALL or 
T-cell lymphoblastic lymphoma (NCT02112916). In adults, recruitment has begun for a phase 2 trial of bortezomib with combination chemotherapy in relapsed/refractory ALL (NCT01769209).

\section{3-JAK inhibitor (Ruxolitinib)}

The JAK/STAT signaling pathway has been identified as a significant mechanism by which leukemic cells bypass normal growth and proliferation restrictions. ${ }^{13}$ In particular, Ph-like ALL appears to be dependent on JAK signaling. The most common rearrangements in Ph-like ALL involve the transmembrane receptor CRLF2, which signals through downstream JAK kinases. Many cytokine receptors, including IL-7 R, act through JAK kinases as well. In addition, JAK1 and JAK2 mutations are found in approximately half of CRLF2-rearranged Ph-like ALL. ${ }^{12-14}$ Preclinical studies have suggested benefit of ruxolitinib for the treatment of Ph-like ALL and CRLF2-rearranged ALL. ${ }^{129,130}$ In addition, ruxolitinib inhibited tumor growth in in vitro and in vivo models of T-ALL with a gain of function in IL-7 R-alpha subunit. ${ }^{131}$ A phase 2 trial of ruxolitinib with standard multi-agent chemotherapy is currently open for recruitment of children, adolescents and adults with newly diagnosed high-risk B-ALL with CRLF2 rearrangements (NCT02723994).

\section{4-Hypomethylating agent (Decitabine)}

DNA methylation is an important epigenetic modification that regulates gene expression. It has long been reported that DNA methylation may play a role in the development of ALL and that methylation status may be used as part of risk stratification. ${ }^{132-135}$ Decitabine is a cytosine analog that inhibits DNA methyltransferase by targeting it for degredation, thus causing hypomethylation of key regulatory domains on DNA. This leads to differentiation and suppression of tumor growth. ${ }^{136}$ Decitabine is currently approved for the treatment of myelodysplastic syndrome (MDS). In a case report, a young girl with her third-relapse of ALL was treated with a decitabine and dexamethasone regimen based on MDS dosing. She was able to undergo Allo-SCT after CR was achieved with re-induction therapy and remained in CR 8 months after transplant. ${ }^{137}$ In a MD Anderson phase I trial of decitabine for relapsed/refractory $A L L$, decitabine was shown to have efficacy when used in combination with Hyper-CVAD for re-induction therapy. ${ }^{138}$ In addition, decitabine monotherapy is well tolerated and thus offers a potential treatment option for relapsed disease in patients that cannot tolerate multi-agent chemotherapy. In a phase 2 study, decitabine and vorinostat (a histone deacetylase inhibitor) were given prior to vincristine, prednisone, PEG-Lasparaginase and doxorubicin for relapsed/refractory ALL. ${ }^{139}$ Results were promising with a CR rate of $50 \%(95 \% \mathrm{Cl}, 15.7-$ $84.3 \%)$ and the OR rate $75 \%$ (95\% Cl, 34.9-96.8\%). Decitabine has also been studied in preclinical trials of early T-cell precursor ALL (ETP-ALL), where it has been shown to be synergistic to conventional chemotherapy. ${ }^{140}$ Decitabine is currently being studied in the post-Allo-SCT setting (NCT02264873) and in combination with clofarabine, idarubicin and cytarabine for relapsed/refractory AML and ALL (NCT01794702).

\section{5-PI3K/mTOR Inhibitors}

The phosphatidylinositol 3-kinase/protein kinase B (PI3K/AKT) and mammalian target of rapamycin (mTOR) pathways are shown to be constitutively activated in $50-75 \%$ of T-ALL. ${ }^{141}$ Preclinical studies suggest that inhibition of the PI3K/AKT/mTOR pathways may be an effective treatment for T-ALL. ${ }^{142-145}$ A dual PI3K/mTOR inhibitor, NVP-BEZ235, potently inhibited the proliferation ALL cells in vitro, causing $G_{0} / G_{1}$ arrest. Moreover, inhibition of proliferation was synergistic when NVP-BEZ235 was combined with cytotoxic agents. ${ }^{144}$ On the basis of this promising preclinical data, several clinical trials are underway to evaluate the use of mTOR and PI3K inhibitors in combination with multi-agent chemotherapy in the frontline and relapsed/refractory setting (NCT01756118, NCT02484430, NCT01523977, NCT01403415, NCT01614197 and NCT01184885).

\section{6-Chimeric antigen receptor (CAR) T cells}

Chimeric antigen receptor-modified (CAR) T cells are genetically engineered T cells that express the antigen-binding domain of an immunoglobulin linked via transmembrane domains to the intracellular T-cell receptor signaling moieties. ${ }^{146}$ This allows the $T$ cells to recognize unprocessed antigens and to be activated in a major histocompatibility complex (MHC)-independent manner. First generation CAR-Ts contain intracellular signaling moieties derived only from the T-cell receptor/CD3 complex. In contrast, second- and third-generation CAR-Ts include co-stimulatory signals in the CAR gene constructs. More recently, fourthgeneration CAR-Ts have been engineered to include a cytokineexpressing cassette.

The process of CAR T-cell therapy involves collecting $T$ cells, introducing the CAR construct, and then an autologous transplant of the modified $T$ cells back into the patient. Options for gene delivery methods include viral vectors and RNA-based methods. ${ }^{147}$ Using a viral vector has the benefit of inducing permanent gene expression and thus offering antitumor activity for as long as the transduced T cells persist. Theoretic risks of this method include malignant transformation of the engineered $T$ cells if the CAR construct is inserted in such a way that it deregulates the expression of an oncogene. ${ }^{148}$ Another method of gene delivery involves direct transfer of an mRNA construct through electroporation. ${ }^{149}$ As no DNA is inserted into the genome of the T-cell, this eliminates the risk of malignant transformation. Given the high replicative potential of these $T$ cells, this methods also offers the advantage of a profound antitumor response. ${ }^{150}$ However, the effects of direct mRNA insertion are transient and antitumor activity rarely persists beyond 7 days. Preclinical studies have suggested a role for RNA-based methods with multiple infusions; however, all current clinical trials utilize a viral vector to deliver the CAR construct. ${ }^{150}$

As mentioned above, CD19 is an ideal target for immunotherapy against B-cell ALL due to its near universal expression on B-lymphoblasts. In a pilot study at the Children's Hospital of Philadelphia, Grupp et al. ${ }^{151}$ treated 53 children with relapsed/ refractory ALL with lymphocyte depleting chemotherapy followed by CD19-directed CAR-Ts. A CR was observed in 50 patients (94\%), with a 12-month EFS rate of $45 \%(95 \% \mathrm{Cl}, 31-66 \%)$ and OS rate of $78 \%$ (95\% Cl, 67-91\%). The CAR-Ts were persistent at 6 months in $68 \%$ of the patients. Nearly all of the patients developed cytokine release syndrome (CRS). The 15 patients in which CRS was severe were effectively treated with the anti-IL-6-receptor antibody, tocilizumab. $^{152}$ Important causes of treatment failure included the loss of circulating CAR-Ts and the expansion of a CD19negative clone. CAR-Ts have also shown activity in adults with relapsed/refractory B-ALL. Davila et al. ${ }^{153}$ treated 16 adults at Memorial Sloan Kettering Cancer Center (MSKCC) with conditioning chemotherapy followed by CD19-directed CAR T-cell infusion. CR was observed in $88 \%$ of patients, with a 1-3 month persistence of CAR-Ts. Lee et al. ${ }^{154}$ reported a $66.7 \% \%$ CR rate in a National Cancer Institute $(\mathrm{NCl})$ intent-to-treat analysis of 20 children and young adults with ALL, with a median CAR-T persistence of 68 days. These data suggest a role for CAR-Ts in the treatment of relapsed/refractory ALL as a bridge to Allo-SCT or to produce durable remission. Limitations include the expansion of CD19negative clones, the lack of long-term persistence of CAR-Ts after a single infusion, and the risk of CRS. Studies are ongoing to identify factors associated with the development of severe CRS and predict patients that would benefit from pretreatment. ${ }^{155,156}$ 
Recently, the application of CAR-T cells has been expanded to CD22-positive B-ALL. Early preclinical studies have showed antitumor activity of CD22-directed CAR-Ts in in vitro and in vivo models that approximates that of CD19-directed CAR-Ts. ${ }^{157}$ Based on these findings, phase 1 trials using CD22-directed CAR-Ts are in the recruiting stages (NCT02650414). Preliminary results of nine patients have demonstrated that therapy is well tolerated and produced a sustained remission at 3 months in all three patients treated with a dose level of $1 \times 10^{6}$ transduced T cells $/ \mathrm{kg}{ }^{158}$

\section{HEMATOPOIETIC STEM CELL TRANSPLANTATION}

After achieving complete response, treatment options include consolidation and maintenance chemotherapy or Allo-SCT for eligible patients. For high-risk patients and patients with relapsed/ refractory disease, Allo-SCT has long been considered the standard of care and best chance for a durable response. While criteria differ between studies, in general high-risk disease is defined as Ph-positive ALL, elevated WBC count, CNS disease, high-risk gene rearrangements, or hypodiploidy. The LALA-94 and City of Hope and Stanford University series have shown a benefit of Allo-SCT over standard chemotherapy in these high-risk patients. ${ }^{49,159,160}$ It is therefore recommended that all high-risk young adults with an available donor undergo Allo-SCT during their first CR (CR1). Recent studies have suggested that patients with ETP-ALL and Ph-like ALL be treated as high-risk and be offered Allo-SCT during CR1 as well. ${ }^{161,162}$ The role of Allo-SCT in standard-risk adults is less clearly defined. In general, MRD has emerged as a prognostic marker that can restratify patients to high-risk, making them candidates for Allo-SCT. Studies $^{32}$ found that MRD-positivity is an independent risk factor for decreased relapse-free and overall survival. Subsequently, other studies ${ }^{163}$ evaluated the risk factors in patients treated with Allo-SCT versus standard chemotherapy after CR1. In patients with positive MRD, Allo-SCT was associated with improved relapse-free survival. However, in patients with a complete MRD response, there was no survival benefit to Allo-SCT over standard chemotherapy. ${ }^{163}$

Allo-SCT also should be considered in all patients that relapse, optimally after achieving a second CR (CR2). The LALA-94 trial showed a 5 -year OS of $33 \%$ in patients who were able to undergo Allo-SCT during CR2 compared to $8 \%$ in patients who underwent Allo-SCT during active relapse. ${ }^{164}$ Patients who are unable to achieve CR2 by conventional methods should be considered for clinical trials with novel agents as a bridge to AlloSCT. In the MRC/ECOG 2993 study, 5-year survival was highest in the group receiving a sibling donor Allo-SCT compared to unmatched donor or chemotherapy alone $(23 \%, 16 \%$ and $4 \%$, respectively). ${ }^{165}$

\section{CONCLUSION}

Acute lymphoblastic leukemia has been touted as a major success story in pediatric oncology through the implementation of doseintensification chemotherapy and Allo-SCT. However, due to highrisk disease characteristics and significant toxicity associated with chemotherapy in adults, outcomes are far less encouraging. There remains much uncertainty about how best to treat adults with $A L L$, as some studies have shown benefit of pediatric-inspired regimens. However, not all adults are able to tolerate such dose intensification and the exact subset of patients who are likely to benefit has not clearly been defined. Furthermore, elderly patients are particularly susceptible to the dose-limiting toxicities of these agents and are often excluded from Allo-SCT on the basis of performance status and medical comorbidities. Novel targeted therapies offer the promise of effective anti-leukemic activity with reduced toxicity from off-target effects. Given the diverse molecular and genetic alterations occurring in ALL, it is unlikely that a single agent will be effective for all patients with ALL. However, with the ability to characterize the immunophenotype and genotype of each patient's leukemia, targeted therapy can be expected to lead to improvements in remission and survival as part of individualized treatment strategies. The successes from tyrosine kinase inhibition in CML have been translated to Ph-positive ALL, and second and third generation TKIs are being studied for use in high-risk Ph-like disease. Other signaling pathways, such as PI3K/AKT/mTOR pathway, are also promising targets for small molecule inhibition. In addition to targeting intracellular pathways, monoclonal antibodies recognize cell surface antigens. Immunoconjugates, such as inotuzumab ozogamicin, bind to leukemic cells, are internalized and release a cytotoxin that kills the leukemic cell; whereas dualspecific antibodies, such as blinatumumab, cause the direct activation of $T$ cells against blasts. CAR-Ts involve a similar mechanism, in which a patient's own $T$ cells are genetically programmed to recognize leukemic cells, inducing an antileukemic immune response. Finally, existing agents, such as bortezomib, decitabine and ruxolitinib that are well tolerated in the treatment of various malignancies are now being studied for application in ALL. As the role of these novel agents is further defined and integrated into new treatment strategies, adult ALL may follow pediatric ALL as a major success story in the near future.

\section{CONFLICT OF INTEREST}

The authors declare no conflict of interest.

\section{REFERENCES}

1 National Cancer Institute. SEER cancer statistics review, 1975-2013:Leukemia, annual incidence rates (acute lymphocytic leukemia).

2 Paul S, Kantarjian H, Jabbour EJ. Adult Acute Lymphoblastic Leukemia. Mayo Clin Proc 2016; 91: 1645-1666.

3 Jabbour E, O'Brien S, Konopleva M, Kantarjian H. New insights into the pathophysiology and therapy of adult acute lymphoblastic leukemia. Cancer 2015; 121: 2517-2528.

4 Shah A, John BM, Sondhi V. Acute lymphoblastic leukemia with treatment--naive Fanconi anemia. Indian Pediatr 2013; 50: 508-510.

5 German J. Bloom's syndrome. XX. The first 100 cancers. Cancer Genet Cytogenet 1997; 93: 100-106.

6 Bielorai B, Fisher T, Waldman D, Lerenthal Y, Nissenkorn A, Tohami T et al. Acute lymphoblastic leukemia in early childhood as the presenting sign of ataxiatelangiectasia variant. Pediatr Hematol Oncol 2013; 30: 574-582.

7 Chessells J, Harrison G, Richards S, Bailey C, Hill F, Gibson B et al. Down's syndrome and acute lymphoblastic leukaemia: clinical features and response to treatment. Arch Dis Child 2001; 85: 321-325.

8 Spector LG, RJ, Robison LL, Bhatia S. Epidemiology and Etiology, Childhood Leukemias, 2nd edition. Cambridge University Press, pp 48-66.

9 Sehgal S, Mujtaba S, Gupta D, Aggarwal R, Marwaha RK. High incidence of Epstein Barr virus infection in childhood acute lymphocytic leukemia: a preliminary study. Indian J Pathol Microbiol 2010; 53: 63-67.

10 Geriniere L, Bastion Y, Dumontet C, Salles G, Espinouse D, Coiffier B. Heterogeneity of acute lymphoblastic leukemia in HIV-seropositive patients. Ann Oncol 1994; 5: 437-440.

11 Mullighan CG, Collins-Underwood JR, Phillips LA, Loudin ML, Liu W, Zhang J et al. Rearrangement of CRLF2 in B-progenitor and down syndrome associated acute lymphoblastic leukemia. Nat Genet 2009; 41: 1243-1246.

12 Mullighan CG, Goorha S, Radtke I, Miller CB, Coustan-Smith E, Dalton JD et al. Genome-wide analysis of genetic alterations in acute lymphoblastic leukaemia. Nature 2007; 446: 758-764.

13 Roberts KG, Morin RD, Zhang J, Hirst M, Zhao Y, Su X et al. Genetic alterations activating kinase and cytokine receptor signaling in high-risk acute lymphoblastic leukemia. Cancer Cell 2012; 22: 153-166.

14 Roberts KG, Li Y, Payne-Turner D, Harvey RC, Yang YL, Pei D et al. Targetable kinase-activating lesions in Ph-like acute lymphoblastic leukemia. $N$ Engl J Med 2014; 371: 1005-1015.

15 Holmfeldt L, Wei L, Diaz-Flores E, Walsh M, Zhang J, Ding L et al. The genomic landscape of hypodiploid acute lymphoblastic leukemia. Nat Genet 2013; 45: 242-252. 
16 Alvarnas JC, Brown PA, Aoun P, Ballen KK, Barta SK, Borate U et al. Acute lymphoid leukemia (version 2.2015). Natl Comprehens Cancer Netw 2015; 13: 1240-1279.

17 Jabbour EJ, Faderl S, Kantarjian HM. Adult acute lymphoblastic leukemia. Mayo Clin Proc 2005; 80: 1517-1527.

18 Bennett JM, Catovsky D, Daniel MT, Flandrin G, Galton DA, Gralnick HR et al. Proposals for the classification of the acute leukaemias. French-American-British (FAB) co-operative group. Br J Haematol 1976; 33: 451-458.

19 Harris NL, Jaffe ES, Diebold J, Flandrin G, Muller-Hermelink HK, Vardiman J et al. World Health Organization classification of neoplastic diseases of the hematopoietic and lymphoid tissues: report of the Clinical Advisory Committee meeting-Airlie House, Virginia, November 1997. J Clin Oncol 1999; 17: 3835-3849.

20 Vardiman JW, Thiele J, Arber DA, Brunning RD, Borowitz MJ, Porwit A et al. The 2008 revision of the World Health Organization (WHO) classification of myeloid neoplasms and acute leukemia: rationale and important changes. Blood 2009; 114: 937-951.

21 Arber DA, Orazi A, Hasserjian R, Thiele J, Borowitz MJ, Le Beau MM et al. The 2016 revision to the World Health Organization classification of myeloid neoplasms and acute leukemia. Blood 2016; 127: 2391-2405.

22 Rowe JM. Prognostic factors in adult acute lymphoblastic leukaemia. $\mathrm{Br} J \mathrm{Hae}$ matol 2010; 150: 389-405.

23 Rowe JM, Buck G, Burnett AK, Chopra R, Wiernik PH, Richards SM et al. Induction therapy for adults with acute lymphoblastic leukemia: results of more than 1500 patients from the international ALL trial: MRC UKALL XII/ECOG E2993. Blood 2005; 106: 3760-3767.

24 Faderl, S HM Kantarjian, et al, T.U.o.T.M.D.A.C.C. Department of Leukemia, Houston, Texas, T.U.o.T.M.D.A.C.C. Department of Leukemia, P.O. Box 428, 1515 Holcombe Blvd., Houston, TX 77030, S. Jeha, T.U.o.T.M.D.A.C.C. Department of Leukemia, Houston, Texas, The biology and therapy of adult acute lymphoblastic leukemia. Cancer, 2017; 98: 1337-1354.

25 Moorman AV, Harrison CJ, Buck GA, Richards SM, Secker-Walker LM, Martineau M et al. Karyotype is an independent prognostic factor in adult acute lymphoblastic leukemia (ALL): analysis of cytogenetic data from patients treated on the Medical Research Council (MRC) UKALLXII/Eastern Cooperative Oncology Group (ECOG) 2993 trial. Blood 2007; 109: 3189-3197.

26 Pullarkat V, Slovak ML, Kopecky KJ, Forman SJ, Appelbaum FR. Impact of cytogenetics on the outcome of adult acute lymphoblastic leukemia: results of Southwest Oncology Group 9400 study. Blood 2008; 111: 2563-2572.

27 Hunger SP, Mullighan CG. Redefining ALL classification: toward detecting highrisk ALL and implementing precision medicine. Blood 2015; 125: 3977-3987.

28 Dongen JJMv, v.d. Velden VHJ, Brüggemann M, Orfao A. Minimal residual disease diagnostics in acute lymphoblastic leukemia: need for sensitive, fast, and standardized technologies. Blood 2015; 125: 3996-4009.

29 Bruggemann M, Raff T, Flohr T, Gokbuget N, Nakao M, Droese J et al. Clinical significance of minimal residual disease quantification in adult patients with standard-risk acute lymphoblastic leukemia. Blood 2006; 107: 1116-1123.

30 Jacquy C, Delepaut B, Van Daele S, Vaerman JL, Zenebergh A, Brichard B et al. A prospective study of minimal residual disease in childhood B-lineage acute lymphoblastic leukaemia: MRD level at the end of induction is a strong predictive factor of relapse. Br J Haematol 1997; 98: 140-146.

31 Sutton R, Venn NC, Tolisano J, Bahar AY, Giles JE, Ashton LJ et al. Clinical significance of minimal residual disease at day 15 and at the end of therapy in childhood acute lymphoblastic leukaemia. Br J Haematol 2009; 146: 292-299.

32 Bassan R, Spinelli O, Oldani E, Intermesoli T, Tosi M, Peruta B et al. Improved risk classification for risk-specific therapy based on the molecular study of minimal residual disease (MRD) in adult acute lymphoblastic leukemia (ALL). Blood 2009; 113: 4153-4162.

33 Campana D. Minimal residual disease in acute lymphoblastic leukemia. Semin Hematol 2009; 46: 100-106.

34 Raff T, Gökbuget N, Lüschen S, Reutzel R, Ritgen M, Irmer S et al. Molecular relapse in adult standard-risk ALL patients detected by prospective MRD monitoring during and after maintenance treatment: data from the GMALL 06/99 and 07/03 trials. Blood 2007; 109: 910-915.

35 Ribera JM, Oriol A, Morgades M, Montesinos P, Sarra J, Gonzalez-Campos J et al. Treatment of high-risk Philadelphia chromosome-negative acute lymphoblastic leukemia in adolescents and adults according to early cytologic response and minimal residual disease after consolidation assessed by flow cytometry: final results of the PETHEMA ALL-AR-03 trial. J Clin Oncol 2014; 32: 1595-1604.

36 Huguet F, Leguay T, Raffoux E, Thomas X, Beldjord K, Delabesse E et al. Pediatricinspired therapy in adults with Philadelphia chromosome-negative acute lymphoblastic leukemia: the GRAALL-2003 study. J Clin Oncol 2009; 27: 911-918.

37 Stock W, La M, Sanford B, Bloomfield CD, Vardiman JW, Gaynon P et al. What determines the outcomes for adolescents and young adults with acute lymphoblastic leukemia treated on cooperative group protocols? A comparison of
Children's Cancer Group and Cancer and Leukemia Group B studies. Blood 2008; 112: $1646-1654$.

38 Scavino HF, George JN, Sears DA. Remission induction in adult acute lymphocytic leukemia. Use of vincristine and prednisone alone. Cancer 1976; 38: 672-677.

39 Gottlieb A, Weinberg V, Ellison R, Henderson E, Terebelo H, Rafla S et al. Efficacy of daunorubicin in the therapy of adult acute lymphocytic leukemia: a prospective randomized trial by cancer and leukemia group B. Blood 1984; 64: 267-274.

40 Larson RA, Dodge RK, Burns CP, Lee EJ, Stone RM, Schulman P et al. A five-drug remission induction regimen with intensive consolidation for adults with acute lymphoblastic leukemia: cancer and leukemia group B study 8811. Blood 1995; 85: 2025-2037.

41 Nagura E, Kimura K, Yamada K, Ota K, Maekawa T, Takaku F et al. Nation-wide randomized comparative study of doxorubicin, vincristine and prednisolone combination therapy with and without L-asparaginase for adult acute lymphoblastic leukemia. Cancer Chemother Pharmacol 1994; 33: 359-365.

42 Short NJ, Jabbour E, Sasaki K, Patel K, O'Brien SM, Cortes JE et al. Impact of complete molecular response on survival in patients with Philadelphia chromosome-positive acute lymphoblastic leukemia. Blood 2016; 128: 504-507.

43 Patel B, Kirkwood A, Dey A, Rowntree C, McMillan A, Marks D et al. Feasibility Of pegylated-asparaginase (PEG-ASP) during induction in adults with acute lymphoblastic leukaemia (ALL): results from the UK Phase 3 Multicentre Trial UKALL 14. 2013.

44 Kantarjian HM, O'Brien S, Smith TL, Cortes J, Giles FJ, Beran M et al. Results of treatment with hyper-CVAD, a dose-intensive regimen, in adult acute lymphocytic leukemia. J Clin Oncol 2000; 18: 547-561.

45 Hurwitz CA, Silverman LB, Schorin MA, Clavell LA, Dalton VK, Glick KM et al. Substituting dexamethasone for prednisone complicates remission induction in children with acute lymphoblastic leukemia. Cancer 2000; 88: 1964-1969.

46 Jones B, Freeman Al, Shuster JJ, Jacquillat C, Weil M, Pochedly C et al. Lower incidence of meningeal leukemia when prednisone is replaced by dexamethasone in the treatment of acute lymphocytic leukemia. Med Pediatr Oncol 1991; 19: 269-275.

47 Narayanan S, Shami PJ. Treatment of acute lymphoblastic leukemia in adults. Crit Rev Oncol Hematol 2012; 81: 94-102.

48 Faderl S, Kantarjian HM, Thomas DA, Cortes J, Giles F, Pierce S et al. Outcome of Philadelphia chromosome-positive adult acute lymphoblastic leukemia. Leuk Lymphoma 2000; 36: 263-273.

49 Dombret H, Gabert J, Boiron JM, Rigal-Huguet F, Blaise D, Thomas X et al. Outcome of treatment in adults with Philadelphia chromosome-positive acute lymphoblastic leukemia--results of the prospective multicenter LALA-94 trial. Blood 2002; 100: 2357-2366.

50 Laport GG, Alvarnas JC, Palmer JM, Snyder DS, Slovak ML, Cherry AM et al. Longterm remission of Philadelphia chromosome-positive acute lymphoblastic leukemia after allogeneic hematopoietic cell transplantation from matched sibling donors: a 20-year experience with the fractionated total body irradiationetoposide regimen. Blood 2008; 112: 903-909.

51 Fielding AK, Rowe JM, Richards SM, Buck G, Moorman AV, Durrant IJ et al. Prospective outcome data on 267 unselected adult patients with Philadelphia chromosome-positive acute lymphoblastic leukemia confirms superiority of allogeneic transplantation over chemotherapy in the pre-imatinib era: results from the International ALL Trial MRC UKALLXII/ECOG2993. Blood 2009; 113: 4489-4496.

52 Thomas DA, Faderl S, Ravandi Kashani F, Wierda WG, Andreeff M, Garris RS et al. Long-term outcome after hyper-CVAD and imatinib (IM) for de novo or minimally treated Philadelphia chromosome-positive acute lymphoblastic leukemia (Ph-ALL)[abstract]. 2010; 28(15 s):abstr 8506:[Available from http://meet inglibrary.asco.org/content/52502-74.

53 Thomas DA, Faderl S, Cortes J, O'Brien S, Giles FJ, Kornblau SM et al. Treatment of Philadelphia chromosome-positive acute lymphocytic leukemia with hyperCVAD and imatinib mesylate. Blood 2004; 103: 4396-4407.

54 Jones D, Thomas D, Yin CC, O'Brien S, Cortes JE, Jabbour E et al. Kinase domain point mutations in Philadelphia chromosome-positive acute lymphoblastic leukemia emerge after therapy with BCR-ABL kinase inhibitors. Cancer 2008; 113: 985-994.

55 Porkka K, Koskenvesa P, Lundan T, Rimpilainen J, Mustjoki S, Smykla R et al. Dasatinib crosses the blood-brain barrier and is an efficient therapy for central nervous system Philadelphia chromosome-positive leukemia. Blood 2008; 112: 1005-1012.

56 Ravandi F, O'Brien SM, Cortes JE, Thomas DM, Garris R, Faderl S et al. Long-term follow-up of a phase 2 study of chemotherapy plus dasatinib for the initial treatment of patients with Philadelphia chromosome-positive acute lymphoblastic leukemia. Cancer 2015; 121: 4158-4164. 
57 Ravandi F, Othus M, O'Brien S, Forman SJ, Ha CS, Wong JYC et al. Multi-Center US Intergroup Study of Intensive Chemotherapy Plus Dasatinib Followed By Allogeneic Stem Cell Transplant in Patients with Philadelphia Chromosome Positive Acute Lymphoblastic Leukemia Younger Than 60. 2015.

58 Ottmann O, Dombret H, Martinelli G, Simonsson B, Guilhot F, Larson RA et al. Dasatinib induces rapid hematologic and cytogenetic responses in adult patients with Philadelphia chromosome-positive acute lymphoblastic leukemia with resistance or intolerance to imatinib: interim results of a phase 2 study. Blood 2007; 110: 2309-2315.

59 Foà R, Vitale A, Vignetti M, Meloni G, Guarini A, Propris MSD et al. Dasatinib as first-line treatment for adult patients with Philadelphia chromosome-positive acute lymphoblastic leukemia. Blood 2011; 118: 6521-6528.

60 Cortes JE, Kim DW, Pinilla-lbarz J, le Coutre P, Paquette R, Chuah C et al. A phase 2 trial of ponatinib in Philadelphia chromosome-positive leukemias. N Engl J Med 2013; 369: 1783-1796.

61 Sasaki K, Jabbour EJ, Ravandi F, Short NJ, Thomas DA, Garcia-Manero G et al. Hyper-CVAD plus ponatinib versus hyper-CVAD plus dasatinib as frontline therapy for patients with Philadelphia chromosome-positive acute lymphoblastic leukemia: A propensity score analysis. Cancer 2016; 122: 3650-3656.

62 Sasaki Koji, Ravandi Farhad, Thomas Deborah A, Cortes Jorge E, Pemmaraju Naveen, Kadia Tapan M et al. Updated results from phase II study of combination of hyper-CVAD (HCVAD) with ponatinib in frontline therapy of patients (pts) with Philadelphia chromosome-positive (Ph+) acute lymphoblastic leukemia (ALL) [abstract]. 2016; 34 s; abstr 7036: Available from http://meetinglibrary.asco.org/ content/167324-176.

63 Nachman J, Siebel N, Sather H, Steinherz P, DeLaat C, Fryer D et al. Outcome for Adolescent and Young Adults 16-21 years of age (AYA) with Acute Lymphoblastic Leukemia (ALL) Treated on the Children's Cancer Group (CCG) 1961 Study. 2004.

64 Stock W, Luger SM, Advani AS, Geyer S, Harvey RC, Mullighan CG et al. Favorable Outcomes for Older Adolescents and Young Adults (AYA) with Acute Lymphoblastic Leukemia (ALL): Early Results of US Intergroup Trial C10403, 2014

65 Rytting ME, Jabbour EJ, Jorgensen JL, Ravandi F, Franklin AR, Kadia TM et al. Final results of a single institution experience with a pediatric-based regimen, the augmented Berlin-Frankfurt-Munster, in adolescents and young adults with acute lymphoblastic leukemia, and comparison to the hyper-CVAD regimen. $A m$ J Hematol 2016; 91: 819-823.

66 Faderl S, Thomas DA, O'Brien S, Ravandi F, Garcia-Manero G, Borthakur G et al. Augmented hyper-CVAD based on dose-intensified vincristine, dexamethasone, and asparaginase in adult acute lymphoblastic leukemia salvage therapy. Clin Lymphoma Myeloma Leuk 2011; 11: 54-59.

67 O'Brien S, Thomas D, Ravandi F, Faderl S, Cortes J, Borthakur G et al. Outcome of Adults With Acute Lymphocytic Leukemia After Second Salvage Therapy. Cancer 2008; 113: 3186-3191.

68 Deitcher OR, O'Brien S, Deitcher SR, Thomas DA, Kantarjian HM. Single-Agent Vincristine Sulfate Liposomes Injection (Marqibo) Compared to Historical SingleAgent Therapy for Adults with Advanced, Relapsed and/or Refractory Philadelphia Chromosome Negative Acute Lymphoblastic Leukemia, 2011.

69 O'Brien S, Schiller G, Lister J, Damon L, Goldberg S, Aulitzky W et al. High-Dose Vincristine Sulfate Liposome Injection for Advanced, Relapsed, and Refractory Adult Philadelphia Chromosome-Negative Acute Lymphoblastic Leukemia. in $J$ Clin Oncol 2013; 31: 676-683.

70 Nagorsen D, Kufer P, Baeuerle PA, Bargou R. Blinatumomab: a historical perspective. Pharmacol Ther 2012; 136: 334-342.

71 Topp MS, Kufer P, Gokbuget N, Goebeler M, Klinger M, Neumann S et al. Targeted therapy with the T-cell-engaging antibody blinatumomab of chemotherapy-refractory minimal residual disease in B-lineage acute lymphoblastic leukemia patients results in high response rate and prolonged leukemiafree survival. J Clin Oncol 2011; 29: 2493-2498.

72 Gökbuget N, Dombret H, Bonifacio M, Reichle A, Graux C, Faul C et al. Long-Term Outcomes after Blinatumomab Treatment: Follow-up of a Phase 2 Study in Patients (Pts) with Minimal Residual Disease (MRD) Positive B-Cell Precursor Acute Lymphoblastic Leukemia (ALL). Blood 2015; 126: 680-680.

73 Topp MS, Gokbuget N, Stein AS, Zugmaier G, O'Brien S, Bargou RC et al. Safety and activity of blinatumomab for adult patients with relapsed or refractory B-precursor acute lymphoblastic leukaemia: a multicentre, single-arm, phase 2 study. Lancet Oncol 2015; 16: 57-66.

74 Kantarjian H, Stein A, Gökbuget N, Fielding AK, Schuh AC, Ribera J-M et al. Blinatumomab versus Chemotherapy for Advanced Acute Lymphoblastic Leukemia. NEJM 2017; 376: 836-847.

75 Martinelli G, Dombret H, Chevallier P, Ottmann OG, Goekbuget N, Topp MS et al. Complete Molecular and Hematologic Response in Adult Patients with Relapsed/ Refractory (R/R) Philadelphia Chromosome-Positive B-Precursor Acute Lymphoblastic Leukemia (ALL) Following Treatment with Blinatumomab: Results from a
Phase 2 Single-Arm, Multicenter Study (ALCANTARA)[Abstract]. Blood 2015; 126: 679.

76 D-ALBA Frontline Sequential Dasatinib and Blinatumomab in Adult Philadelphia Positive Acute Lymphoblastic Leukemia - Full Text View - ClinicalTrials.gov. 2017; Available at: https://clinicaltrials.gov/ct2/show/NCT02744768.

77 DeAngelo DJ, Yu D, Johnson JL, Coutre SE, Stone RM, Stopeck AT et al. Nelarabine induces complete remissions in adults with relapsed or refractory T-lineage acute lymphoblastic leukemia or lymphoblastic lymphoma: Cancer and Leukemia Group B study 19801. Blood 2007; 109: 5136-5142.

78 Shah NN, Stevenson MS, Yuan CM, Richards K, Delbrook C, Kreitman RJ et al. Characterization of CD22 expression in acute lymphoblastic leukemia. Pediatr Blood Cancer 2015; 62: 964-969.

79 Piccaluga PP, Arpinati M, Candoni A, Laterza C, Paolini S, Gazzola A et al. Surface antigens analysis reveals significant expression of candidate targets for immunotherapy in adult acute lymphoid leukemia. Leuk Lymphoma 2011; 52: 325-327.

80 Chevallier P, Robillard N, Houille G, Ayari S, Guillaume T, Delaunay J et al. Simultaneous study of five candidate target antigens (CD20, CD22, CD33, CD52, HER2) for antibody-based immunotherapy in B-ALL: a monocentric study of 44 cases. in Leukemia 2009; England pp 806-807.

81 Carnahan J, Wang P, Kendall R, Chen C, Hu S, Boone T et al. Epratuzumab, a humanized monoclonal antibody targeting CD22: characterization of in vitro properties. Clin Cancer Res 2003; 9(10 Pt 2): 3982s-3990ss.

82 Raetz EA, Cairo MS, Borowitz MJ, Blaney SM, Krailo MD, Leil TA et al. Chemoimmunotherapy reinduction with epratuzumab in children with acute lymphoblastic leukemia in marrow relapse: a Children's Oncology Group Pilot Study. J Clin Oncol 2008; 26: 3756-3762.

83 Advani AS, McDonough S, Coutre S, Wood B, Radich J, Mims M et al. SWOG S0910: a phase 2 trial of clofarabine/cytarabine/epratuzumab for relapsed/ refractory acute lymphocytic leukaemia. Br J Haematol 2014; 165: 504-509.

84 Sharkey RM, Govindan SV, Cardillo TM, Goldenberg DM. Epratuzumab-SN-38: A New Antibody-Drug Conjugate for the Therapy of Hematologic Malignancies. Mol Cancer Ther 2012; 11: 224-234.

85 Hinman LM, Hamann PR, Wallace R, Menendez AT, Durr FE, Upeslacis J. Preparation and characterization of monoclonal antibody conjugates of the calicheamicins: a novel and potent family of antitumor antibiotics. Cancer Res 1993; 53: 3336-3342.

86 DiJoseph JF, Armellino DC, Boghaert ER, Khandke K, Dougher MM, Sridharan L et al. Antibody-targeted chemotherapy with CMC-544: a CD22-targeted immunoconjugate of calicheamicin for the treatment of B-lymphoid malignancies. Blood 2004; 103: 1807-1814.

87 Advani A, Coiffier B, Czuczman MS, Dreyling M, Foran J, Gine E et al. Safety, pharmacokinetics, and preliminary clinical activity of inotuzumab ozogamicin, a novel immunoconjugate for the treatment of B-cell non-Hodgkin's lymphoma: results of a phase I study. J Clin Oncol 2010; 28: 2085-2093.

88 Kantarjian H, Thomas D, Jorgensen J, Jabbour E, Kebriaei P, Rytting $M$ et al. Inotuzumab ozogamicin, an anti-CD22-calecheamicin conjugate, for refractory and relapsed acute lymphocytic leukaemia: a phase 2 study. Lancet Oncol 2012; 13: 403-411.

89 Kantarjian $\mathrm{H}$, Thomas $\mathrm{D}$, Jorgensen J, Kebriaei $\mathrm{P}$, Jabbour E, Rytting $\mathrm{M}$ et al. Results of inotuzumab ozogamicin, a CD22 monoclonal antibody, in refractory and relapsed acute lymphocytic leukemia. Cancer 2013; 119: 2728-2736.

90 Advani AS, Stein AS, Kantarjian HM, Shustov AR, DeAngelo DJ, Ananthakrishnan $\mathrm{R}$ et al. A Phase II Study of Weekly Inotuzumab Ozogamicin (InO) in Adult Patients with CD22-Positive Acute Lymphoblastic Leukemia (ALL) in Second or Later Salvage. Blood 2014; 124: 2255.

91 Kantarjian HM, DeAngelo DJ, Stelljes M, Martinelli G, Liedtke M, Stock W et al. Inotuzumab Ozogamicin versus Standard Therapy for Acute Lymphoblastic Leukemia. N Engl J Med 2016; 375: 740-753.

92 Jabbour E, O'Brien S, Thomas D, Sasaki K, Garcia-Manero G, Ravandi F et al. Inotuzumab Ozogamicin (IO) in Combination with Low-Intensity Chemotherapy (mini-hyper-CVD) as Frontline Therapy for Older Patients (pts) and as Salvage Therapy for Adult with Relapsed/Refractory (R/R) Acute Lymphoblastic Leukemia (ALL). Clin Lymphoma Myeloma Leuk 2015, 15.

93 Kreitman RJ, Pastan I. Antibody Fusion Proteins: Anti-CD22 Recombinant Immunotoxin Moxetumomab Pasudotox. Clin Cancer Res 2011; 17: 6398-6405.

94 Kreitman RJ, Stetler-Stevenson M, Margulies I, Noel P, FitzGerald DJP, Wilson WH et al. Phase II Trial of Recombinant Immunotoxin RFB4(dsFv)-PE38 (BL22) in Patients With Hairy Cell Leukemia. J Clin Oncol 2009; 27: 2983-2990.

95 Wayne AS, Kreitman RJ, Findley HW, Lew G, Delbrook C, Steinberg SM et al. AntiCD22 Immunotoxin RFB4(dsFv)-PE38 (BL22) for CD22-Positive Hematologic Malignancies of Childhood: Preclinical Studies and Phase I Clinical Trial. Clin Cancer Res 2010; 16: 1894-1903. 
96 Wayne AS, Bhojwani D, Silverman LB, Richards K, Stetler-Stevenson M, Shah NN et al. A Novel Anti-CD22 Immunotoxin, Moxetumomab Pasudotox: Phase I Study in Pediatric Acute Lymphoblastic Leukemia (ALL). Blood 2011; 118: 248.

97 Ravandi F, Kantarjian HM, Goswami T, Wang F, Ibrahim R. Design Of a Phase 1/2 Study Of Moxetumomab Pasudotox In Adult Patients With Relapsed and/Or Refractory Acute Lymphoblastic Leukemia (ALL). Blood 2013; 122: 5021.

98 Herrera L, Bostrom B, Gore L, Sandler E, Lew G, Schlegel PG et al. A phase 1 study of Combotox in pediatric patients with refractory B-lineage acute lymphoblastic leukemia. J Pediatr Hematol Oncol 2009; 31: 936-941.

99 Schindler J, Gajavelli S, Ravandi F, Shen Y, Parekh S, Braunchweig I et al. A Phase I Study of a Combination of anti-CD19 and anti-CD22 Immunotoxins (Combotox) in Adult Patients with Refractory B-Lineage Acute Lymphoblastic Leukaemia. Br J Haematol 2011; 154: 471-476.

100 Thomas DA, O'Brien S, Jorgensen JL, Cortes J, Faderl S, Garcia-Manero G et al. Prognostic significance of CD20 expression in adults with de novo precursor B-lineage acute lymphoblastic leukemia. Blood 13: 6330-6337.

101 Wierda WG, Padmanabhan S, Chan GW, Gupta IV, Lisby S, Österborg A et al. Ofatumumab is active in patients with fludarabine-refractory CLL irrespective of prior rituximab: results from the phase 2 international study. Blood 2011; 118: 5126-5129.

102 Teeling JL, French RR, Cragg MS, v.d. Brakel J, Pluyter M, Huang $\mathrm{H}$ et al. Characterization of new human CD20 monoclonal antibodies with potent cytolytic activity against non-Hodgkin lymphomas. Blood 2004; 104: 1793-1800.

103 Pawluczkowycz AW, Beurskens FJ, Beum PV, Lindorfer MA, v.d. Winkel JGJ, Parren PWHI et al. Binding of Submaximal C1q Promotes ComplementDependent Cytotoxicity (CDC) of B Cells Opsonized with Anti-CD20 mAbs Ofatumumab (OFA) or Rituximab (RTX): Considerably Higher Levels of CDC Are Induced by OFA than by RTX. J Immunol 2009; 183: 749-758.

104 Jabbour E, Hagop K, Thomas D, Garcia-Manero G, Hoehn D, Garris R et al. Phase II Study Of The Hyper-CVAD Regimen In Combination With Ofatumumab As Frontline Therapy For Adults With CD-20 Positive Acute Lymphoblastic Leukemia (ALL). Blood 2013; 122: 2664.

105 Sasaki K, Kantarjian HM, Ravandi F, Daver N, Kadia TM, Khouri RB et al. Frontline Ofatumumab in Combination with Hyper-CVAD for Adult Patients with CD-20 Positive Acute Lymphoblastic Leukemia (ALL): Interim Result of a Phase II Clinical Trial. Poster presented at the American Society of Hematology 58th Annual Meeting and Exposition. 2 December 2016, San Diego, CA, USA, 2016.

106 Thomas DA, O'Brien S, Faderl S, Garcia-Manero G, Ferrajoli A, Wierda W et al. Chemoimmunotherapy With a Modified Hyper-CVAD and Rituximab Regimen Improves Outcome in De Novo Philadelphia Chromosome-Negative Precursor B-Lineage Acute Lymphoblastic Leukemia. J Clin Oncol 2010; 28: 3880-3889.

107 Herter S, Herting F, Mundigl O, Waldhauer I, Weinzierl T, Fauti T et al. Preclinical activity of the type II CD20 antibody GA101 (obinutuzumab) compared with rituximab and ofatumumab in vitro and in xenograft models. Mol Cancer Ther 2013; 12: 2031-2042.

108 Awasthi A, Ayello J, Van de Ven C, Elmacken M, Sabulski A, Barth MJ et al. Obinutuzumab (GA101) compared to rituximab significantly enhances cell death and antibody-dependent cytotoxicity and improves overall survival against $\mathrm{CD} 20(+)$ rituximab-sensitive/-resistant Burkitt lymphoma (BL) and precursor B-acute lymphoblastic leukaemia (pre-B-ALL): potential targeted therapy in patients with poor risk CD20(+) BL and pre-B-ALL. Br J Haematol 2015; 171: 763-775.

109 Goede V, Fischer K, Busch R, Engelke A, Eichhorst B, Wendtner CM et al. Obinutuzumab plus Chlorambucil in Patients with CLL and Coexisting Conditions. N Engl J Med 2014; 370: 1101-1110.

110 Smith EJ, Olson K, Haber LJ, Varghese B, Duramad P, Tustian AD et al. A novel, native-format bispecific antibody triggering T-cell killing of B-cells is robustly active in mouse tumor models and cynomolgus monkeys. Scientific Reports, Published online 2015; 5: 17943, 2015.

111 Bannerji R, Brown JR, Advani RH, Arnason J, O'Brien SM, Allan JN et al. Phase 1 Study of REGN1979, an Anti-CD20 x Anti-CD3 Bispecific Monoclonal Antibody, in Patients with CD20+ B-Cell Malignancies Previously Treated with CD20-Directed Antibody Therapy. Blood 2016; 128: 621.

112 Fujimoto M, Poe JC, Jansen PJ, Sato S, Tedder TF. CD19 amplifies B lymphocyte signal transduction by regulating Src-family protein tyrosine kinase activation. J Immunol 1999; 162: 7088-7094.

113 Otero DC, Omori SA, Rickert RC. CD19-dependent Activation of Akt Kinase in B-lymphocytes. J Biol Chem 2001; 276: 1474-1478.

114 Chung EY, Psathas JN, Yu D, Li Y, Weiss MJ, Thomas-Tikhonenko A. CD19 is a major B cell receptor-independent activator of MYC-driven B-lymphomagenesis. J Clin Invest 2012; 122: 2257-2266.

115 Ning BT, Tang YM, Chen YH, Shen HQ, Qian BQ. Comparison between CD19 and CD20 expression patterns on acute leukemic cells. Zhongguo Shi Yan Xue Ye Xue Za Zhi 2005; 13: 943-947.
116 Widdison Wayne C, Wilhelm Sharon D, Cavanagh Emily E, Whiteman Kathleen R, Leece Barbara A, Kovtun Yelena et al. Semisynthetic Maytansine Analogues for the Targeted Treatment of Cancer. J Med Chem 2006; 49: 4392-4408.

117 Carol H, Szymanska B, Evans K, Boehm I, Houghton PJ, Smith MA et al. The AntiCD19 Antibody-Drug Conjugate SAR3419 Prevents Hematolymphoid Relapse Postinduction Therapy in Preclinical Models of Pediatric Acute Lymphoblastic Leukemia. Clin Cancer Res 2013; 19: 1795-1805.

118 Younes A, Kim S, Romaguera J, Copeland A, Farial Sdc, Kwak LW et al. Phase I Multidose-Escalation Study of the Anti-CD19 Maytansinoid Immunoconjugate SAR3419 Administered by Intravenous Infusion Every 3 Weeks to Patients With Relapsed/Refractory B-Cell Lymphoma. Blood 2009; 114: 585.

119 Kantarjian HM, Lioure B, Kim SK, Atallah E, Leguay T, Kelly K et al. A Phase II Study of Coltuximab Ravtansine (SAR3419) Monotherapy in Patients With Relapsed or Refractory Acute Lymphoblastic Leukemia. Clin Lymphoma Myeloma Leuk 2016; 16: 139-145.

120 Fathi AT, Borate U, DeAngelo DJ, O'Brien MM, Trippett T, Shah BD et al. A Phase 1 Study of Denintuzumab Mafodotin (SGN-CD19A) in Adults with Relapsed or Refractory B-Lineage Acute Leukemia (B-ALL) and Highly Aggressive Lymphoma. Blood 2015; 126: 1328.

121 Zammarchi F, Williams DG, Adams L, Havenith K, Chivers S, D'Hooge F et al. PreClinical Development of Adct-402, a Novel Pyrrolobenzodiazepine (PBD)-Based Antibody Drug Conjugate (ADC) Targeting CD19-Expressing B-Cell Malignancies. Blood 2015; 126: 1564.

122 Flynn MJ, Pv Berkel, Zammarchi F, Levy J-N, Tiberghien A, Masterson LA et al. Pre-Clinical Activity of Adct-301, a Novel Pyrrolobenzodiazepine (PBD) DimerContaining Antibody Drug Conjugate (ADC) Targeting CD25-Expressing Hematological Malignancies. Blood 2014; 124: 4491.

123 Flynn MJ, Berkel PHv, Zammarchi F, Tyrer PC, Akarca AU, Janghra N et al. PreClinical Activity of Adct-301, a Novel Pyrrolobenzodiazepine (PBD) Dimer-Containing Antibody Drug Conjugate (ADC) Targeting CD25-Expressing Hematological Malignancies. Blood 2014; 124: 4491.

124 Owaidah TM, Rawas FI, Al Khayatt MF, Elkum NB. Expression of CD66c and CD25 in acute lymphoblastic leukemia as a predictor of the presence of BCR/ABL rearrangement. Hematol Oncol Stem Cell Ther 2008; 1: 34-37.

125 Horton TM, Gannavarapu A, Blaney SM, D'Argenio DZ, Plon SE, Berg SL. Bortezomib interactions with chemotherapy agents in acute leukemia in vitro. Cancer Chemother Pharmacol 2006; 58: 13-23.

126 Cortes J, Thomas D, Koller C, Giles F, Estey E, Faderl S et al. Phase I Study of Bortezomib in Refractory or Relapsed Acute Leukemias. Clin Cancer Res 2004; 10: 3371-3376.

127 Messinger YH, Gaynon PS, Sposto R, v.d. Giessen J, Eckroth E, Malvar J et al. Bortezomib with chemotherapy is highly active in advanced B-precursor acute lymphoblastic leukemia: Therapeutic Advances in Childhood Leukemia \& Lymphoma (TACL) Study. Blood 2012; 120: 285-290.

128 Horton Terzah M, O'Brien Maureen Megan, Borowitz Michael J, Devidas Meenakshi, Raetz Elizabeth A, Brown Patrick Andrew et al. Bortezomib reinduction therapy to improve response rates in pediatric ALL in first relapse: A Childrenâ?'s Oncology Group (COG) study (AALL07P1) [Abstract]. 2013; Available at: http:// meetinglibrary.asco.org/content/111816-132.

129 Maude SL, Tasian SK, Vincent T, Hall JW, Sheen C, Roberts KG et al. Targeting JAK $1 / 2$ and mTOR in murine xenograft models of Ph-like acute lymphoblastic leukemia. Blood 2012; 120: 3510-3518.

130 Tasian SK, Doral MY, Borowitz MJ, Wood BL, Chen IM, Harvey RC et al. Aberrant STAT5 and PI3K/mTOR pathway signaling occurs in human CRLF2rearranged B-precursor acute lymphoblastic leukemia. Blood 2012; 120: 833-842.

131 Senkevitch E, Hixon J, Andrews C, Barata JT, Li W, Durum S. The JAK Inhibitor Ruxolitinib Is Effective in Treating T Cell Acute Lymphoblastic Leukemia with Gain of Function Mutations in IL-7R Alpha. Blood 2015; 126: 1330.

132 Nordlund J, Milani L, Lundmark A, Lonnerholm G, Syvanen AC. DNA methylation analysis of bone marrow cells at diagnosis of acute lymphoblastic leukemia and at remission. PLoS One 2012; 7: e34513.

133 Nordlund J, Backlin CL, Zachariadis V, Cavelier L, Dahlberg J, Ofverholm I et al. DNA methylation-based subtype prediction for pediatric acute lymphoblastic leukemia. Clin Epigenetics 2015; 7: 11.

134 Chatterton Z, Morenos L, Mechinaud F, Ashley DM, Craig JM, Sexton-Oates A et al. Epigenetic deregulation in pediatric acute lymphoblastic leukemia. Epigenetics 2014; 9: 459-467.

135 Milani L, Lundmark A, Kiialainen A, Nordlund J, Flaegstad T, Forestier E et al. DNA methylation for subtype classification and prediction of treatment outcome in patients with childhood acute lymphoblastic leukemia. Blood 2010; 115: 1214-1225.

136 Issa J-PJ. DNA Methylation as a Therapeutic Target in Cancer. Clin Cancer Res 2007; 13: 1634-1637 
137 Yánez L, Bermúdez A, Richard C, Bureo E, Iriondo A. Successful induction therapy with decitabine in refractory childhood acute lymphoblastic leukemia. Leukemia 2009; 23: 1342-1343.

138 Benton CB, Thomas DA, Yang H, Ravandi F, Rytting M, O'Brien S et al. Safety and clinical activity of 5-aza-2'-deoxycytidine (decitabine) with or without HyperCVAD in relapsed/refractory acute lymphocytic leukaemia. Br J Haematol 2014; 167: 356-365.

139 Burke MJ, Lamba JK, Pounds S, Cao X, Ghodke-Puranik Y, Lindgren BR et al. A therapeutic trial of decitabine and vorinostat in combination with chemotherapy for relapsed/refractory acute lymphoblastic leukemia. Am J Hematol 2014; 89: 889-895.

140 Lu BY, Thanawala SU, Zochowski KC, Burke MJ, Carroll WL, Bhatla T. Decitabine enhances chemosensitivity of early T-cell precursor-acute lymphoblastic leukemia cell lines and patient-derived samples. Leuk Lymphoma 2016; 57: 1938-1941.

141 Zhao WL. Targeted therapy in T-cell malignancies: dysregulation of the cellular signaling pathways. Leukemia 2010; 24: 13-21.

142 Chiarini F, Fala F, Tazzari PL, Ricci F, Astolfi A, Pession A et al. Dual inhibition of class IA phosphatidylinositol 3-kinase and mammalian target of rapamycin as a new therapeutic option for T-cell acute lymphoblastic leukemia. Cancer Res 2009; 69: 3520-3528.

143 Bressanin D, Evangelisti C, Ricci F, Tabellini G, Chiarini F, Tazzari PL et al. Harnessing the $\mathrm{PI3K} / \mathrm{Akt} / \mathrm{mTOR}$ pathway in T-cell acute lymphoblastic leukemia: Eliminating activity by targeting at different levels. Oncotarget 2012; 3: 811-823.

144 Schult C, Dahlhaus M, Glass A, Fischer K, Lange S, Freund M et al. The dual kinase inhibitor NVP-BEZ235 in combination with cytotoxic drugs exerts antiproliferative activity towards acute lymphoblastic leukemia cells. Anticancer Res 2012; 32: 463-474.

145 Saunders P, Cisterne A, Weiss J, Bradstock KF, Bendall LJ. The mammalian target of rapamycin inhibitor RAD001 (everolimus) synergizes with chemotherapeutic agents, ionizing radiation and proteasome inhibitors in pre-B acute lymphocytic leukemia. Haematologica 2011; 96: 69-77.

146 Dai H, Wang Y, Lu X, Han W. Chimeric Antigen Receptors Modified T-Cells for Cancer Therapy. Natl Cancer Inst 2016; 108: pii djv439.

147 Maude SL, Teachey DT, Porter DL, Grupp SA. CD19-targeted chimeric antigen receptor T-cell therapy for acute lymphoblastic leukemia. Blood 2015; 125: 4017-4023.

148 Suerth JD, Schambach A, Baum C. Genetic modification of lymphocytes by retrovirus-based vectors. Curr Opin Immunol 2012; 24: 598-608.

149 Riet T, Holzinger A, Dorrie J, Schaft N, Schuler G, Abken H. Nonviral RNA transfection to transiently modify $T$ cells with chimeric antigen receptors for adoptive therapy. Methods Mol Biol 2013; 969: 187-201.

150 Barrett DM, Liu X, Jiang S, June CH, Grupp SA, Zhao Y. Regimen-specific effects of RNA-modified chimeric antigen receptor $T$ cells in mice with advanced leukemia. Hum Gene Ther 2013; 24: 717-727.

151 Grupp SA, Maude SL, Shaw PA, Aplenc R, Barrett DM, Callahan C et al. Durable Remissions in Children with Relapsed/Refractory ALL Treated with T Cells Engineered with a CD19-Targeted Chimeric Antigen Receptor (CTL019). Blood 2015; 126: 681-681.

152 Maude SL, Frey N, Shaw PA, Aplenc R, Barrett DM, Bunin NJ et al. Chimeric antigen receptor T cells for sustained remissions in leukemia. N Engl J Med 2014; 371: 1507-1517.

153 Davila ML, Riviere I, Wang X, Bartido S, Park J, Curran K et al. Efficacy and Toxicity Management of 19-28z CAR T Cell Therapy in B Cell Acute Lymphoblastic Leukemia. Sci Transl Med 2014; 6: 224ra25.
154 Lee DW, Kochenderfer JN, Stetler-Stevenson M, Cui YK, Delbrook C, Feldman SA et al. T cells expressing CD19 chimeric antigen receptors for acute lymphoblastic leukaemia in children and young adults: a phase 1 dose-escalation trial. Lancet 2015; 385: 517-528.

155 Maude SL, Barrett D, Teachey DT, Grupp. SA. Managing Cytokine Release Syndrome Associated With Novel T Cell-Engaging Therapies. Cancer J 2014; 20: $119-122$.

156 Lee DW, Gardner R, Porter DL, Louis CU, Ahmed N, Jensen M et al. Current concepts in the diagnosis and management of cytokine release syndrome. Blood 2014; 124: 188-195.

157 Haso W, Lee DW, Shah NN, Stetler-Stevenson M, Yuan CM, Pastan IH et al. AntiCD22-chimeric antigen receptors targeting B-cell precursor acute lymphoblastic leukemia. Blood 2013; 1165-1174.

158 Shah NN, Stetler-Stevenson M, Yuan CM, Shalabi H, Yates B, Delbrook C et al. Minimal Residual Disease Negative Complete Remissions Following Anti-CD22 Chimeric Antigen Receptor (CAR) in Children and Young Adults with Relapsed/ Refractory Acute Lymphoblastic Leukemia (ALL). Blood 2016; 128: 650.

159 Jamieson CH, Amylon MD, Wong RM, Blume KG. Allogeneic hematopoietic cell transplantation for patients with high-risk acute lymphoblastic leukemia in first or second complete remission using fractionated total-body irradiation and high-dose etoposide: a 15-year experience. Exp Hematol 2003; 31: 981-986.

160 Thomas X, Boiron JM, Huguet F, Dombret H, Bradstock K, Vey N et al. Outcome of treatment in adults with acute lymphoblastic leukemia: analysis of the LALA-94 trial. J Clin Oncol 2004; 22: 4075-4086.

161 Jain N, Lamb AV, O'Brien S, Ravandi F, Konopleva M, Jabbour E et al. Early T-cell precursor acute lymphoblastic leukemia/lymphoma (ETP-ALL/ LBL) in adolescents and adults: a high-risk subtype. Blood 2016; 127: 1863-1869.

162 Gokbuget N, Kneba M, Raff T, Trautmann H, Bartram CR, Arnold R et al. Adult patients with acute lymphoblastic leukemia and molecular failure display a poor prognosis and are candidates for stem cell transplantation and targeted therapies. Blood 2012; 120: 1868-1876.

163 Dhedin N, Huynh A, Maury S, Tabrizi R, Beldjord K, Asnafi V et al. Role of allogeneic stem cell transplantation in adult patients with Ph-negative acute lymphoblastic leukemia. Blood 2015; 125: 2486-2496, quiz 2586.

164 Tavernier E, Boiron JM, Huguet F, Bradstock K, Vey N, Kovacsovics T et al. Outcome of treatment after first relapse in adults with acute lymphoblastic leukemia initially treated by the LALA-94 trial. Leukemia 2007; 21: 1907-1914.

165 Fielding AK, Richards SM, Chopra R, Lazarus HM, Litzow MR, Buck G et al. Outcome of 609 adults after relapse of acute lymphoblastic leukemia (ALL); an MRC UKALL12/ECOG 2993 study. Blood 2007; 109: 944-950.

(i) This work is licensed under a Creative Commons Attribution 4.0 International License. The images or other third party material in this article are included in the article's Creative Commons license, unless indicated otherwise in the credit line; if the material is not included under the Creative Commons license, users will need to obtain permission from the license holder to reproduce the material. To view a copy of this license, visit http://creativecommons.org/licenses/ by/4.0/

(c) The Author(s) 2017 